ANUARIO DE Estudios MEdiEVALES 44/1, enero-junio de 2014, pp. 241-276

ISSN 0066-5061

doi:10.3989/aem.2014.44.1.08

\title{
DIALOGAR CON DIOS: EL USO DE LAS IMÁGENES EN LOS CONVENTOS FEMENINOS DE DOMINICAS EN LA TEUTONIA BAJOMEDIEVAL
}

\author{
TALKING TO GOD: \\ THE USE OF IMAGES IN THE DOMINICAN NUNNERIES \\ OF LATE MEDIEVAL TEUTONIA
}

CAROLA JÄGGI

Kunsthistorisches Institut der Universität Zürich

\begin{abstract}
Resumen: Procedentes de la antigua provincia dominica alto alemana han llegado hasta nosotros algunos Schwesternbücher o Libros de monjas ${ }^{1}$ de los siglos XIV y $\mathrm{XV}$ que ofrecen interesantes indicaciones sobre el uso que se hacía en los conventos de mujeres de la Baja edad Media de las obras de arte que en ellos se custodiaban. Entre otras cosas se desprende de estas fuentes que las hermanas utilizaban las imágenes no siempre y no sólo como instrumentos de meditación para conmemorar los acontecimientos de la Historia de Salvación, sino sobre todo acudían en tiempos de necesidad a las imágenes de la Madre de Dios y del crucifijo para obtener de ellas consejo y consuelo. Parece por consiguiente que se trata de una forma de comprensión de la imagen que unía el arquetipo original y su representación, "morando" el representado en su imagen. Casos como el de St. Katharinental en el noreste de Suiza, donde además de las fuentes escritas se ha conservado un buen número de tallas del siglo XIV, son especialmente interesantes para esta cuestión.
\end{abstract}

\begin{abstract}
Several convent chronicles from within the Dominican Province of Upper Germany dating back to the 14th and 15th centuries provide interesting insight into the manner in which works of art were utilized in late medieval religious life. Amongst other findings, study of the sources reveals that the nuns used images of the Mother of God and of the Crucified Christ not always and not only to meditate upon and commemorate the facts of salvation, but above all to receive support and solace in times of distress. The conception of icons derived from these sources is of the merging of archetype and image and of the indwelling of the person depicted in the image. Examples such as St Katharinental in northeastern Switzerland, where a large supply of images has been preserved in addition to numerous statues, are of particular interest for the study.
\end{abstract}

\footnotetext{
1 Nota de la traductora: he traducido Schwesternbuch por Libro de monjas. Los Schwesternbücher o Libros de monjas son un género literario también denominado Gnadenviten o Schwesternviten (Biografias de la Gracia divina o Vidas de monjas) que combina elementos de hagiografía, crónica y leyenda fundacional. Estos textos son característicos de los países de habla alemana en los siglos XIV y XV, especialmente de los conventos de dominicas de la actual Alemania del sur y de Suiza. El artículo ha sido traducido del alemán por Blanca Garí.
} 
Palabras clave: imágenes devocionales; espiritualidad femenina; prácticas de veneración; conventos de mujeres; dominicas; escultura; frescos-pinturas murales; libros; St. Katharinental.
Keywords: devotional image; spirituality of women; veneration practices; Dominican convents; sculpture; frescoes/ mural paintings; convent chronicles; $\mathrm{St}$ Katharinental.

\section{SUMARIO}

1. Introducción.- 2. Los Libros de monjas de Teutonia como fuente.- 3. St. Katharinental : un caso por excelencia.- 4. Töss, Engeltal, Kirchberg \& Co.- 5. Resumen y conclusión.- 6 Bibliografía citada.

\section{INTRODUCCIÓN}

Como consecuencia del precepto de clausura estricta que acompañó el monacato femenino desde comienzos del siglo $\mathrm{V}$ y que el papa Bonifacio VIII hizo extensible en 1298 a todas las ordenes femeninas, las iglesias de las monjas de los últimos siglos medievales presentaban un espacio que no existía de forma idéntica en las iglesias monásticas masculinas contemporáneas: el coro de las monjas ${ }^{2}$. Ciertamente también los monjes tenían a su disposición en el interior de sus iglesias un coro que les permitía llevar a cabo el rezo de las horas con relativo recogimiento, separados de los posibles laicos y conversos allí presentes. Mas, puesto que los monjes -al contrario que las monjas- estaban también facultados para el servicio divino y, en concreto, podían y debían celebrar misa, su coro se encontraba a menudo en la inmediata vecindad del presbiterio e incluso se confundía con él en una única unidad espacial. No así en los conventos femeninos: en ellos, dado que las sores no solo debían ser protegidas y separadas del público laico sino también, según el precepto de clausura restrictiva, del sacerdote celebrante, el coro se encontraba en la mayoría de los casos a una cierta distancia del presbiterio: en Alemania y en Europa oriental las más de las veces alzado en una galeria en la parte oeste de la nave, mientras que en el Alto Rin, en Suiza y en Italia estaba situado normalmente en la parte este de la iglesia propiamente dicha, separado

${ }^{2}$ El presente artículo tiene su origen en una conferencia, que fue impartida en 2002 en las Jornadas "Art, femmes et religion" en Colmar y publicada en alemán en 2004 (C. Jäggi, "Sy bettet och gewonlich vor únser frowen bild..."). En los años siguientes, el texto, reelaborado y ampliado en la forma que aquí se presenta, ha servido de base para conferencias impartidas en diversas universidades (Universidad de Hamburgo y la Sapienza de Roma). Sobre los coros de las monjas y sobre todas las implicaciones relacionadas con ellos véase C. Jäggi, Frauenklöster im Spätmittelalter. Véase también C. Jäggi, Architecture et disposition; idem, Eastern Choir or Western Gallery? 
de ella por un coro alto o una auténtica pared. Ambas soluciones tenían en común que las monjas quedaban claramente separadas del altar en el cual se celebraba cotidianamente la misa conventual. Por consiguiente solo de forma muy limitada podían participar visualmente en la misa y seguir ópticamente lo que acontecía en el altar. A lo sumo una pequeña ventana que se abría durante la celebración de la misa les permitía una rápida mirada a la Hostia en el momento de la transubstanciación en la elevación eucarística en manos del sacerdote. Pero en general, para las monjas sentadas en sus sillas del coro la vista del altar era muy parcial, cuando no imposible. Por ello, se ha señalado en ocasiones las estrategias compensatorias que parecen haberse establecido en los conventos femeninos ${ }^{3}$. En algunos casos, allí donde el coro de las monjas disponía de pinturas murales, se puede suponer que durante la misa, a falta de campo visual sobre el altar, las hermanas contemplaban los frescos de su coro y asociaban en espíritu lo oído con lo visto, utilizando las imágenes como transfondo de lo que acontecía en el altar, perceptible solo auditivamen$\mathrm{te}^{4}$. Thomas Lentes va incluso más lejos llegando a ver en el uso que las monjas medievales hacían de las obras de arte de sus monasterios claros paralelismos con la teología sacramental. Para las monjas -afirma la tesis de Lentes

la imagen era sacramento, lugar de encuentro con lo sagrado. Sus devoción a las imágenes serían así una extensión de la acción eclesiástico sacramental, cuyo acceso permanecía vedado para las monjas. (...) La oración devocional de las monjas, sea ante una imagen externa o mediante la imaginación, se convirtió en la Edad Media en una analogía del sacrificio de la misa ${ }^{5}$.

Esto significaría, sin embargo, que en los conventos de mujeres, como consecuencia casi natural de la exclusión de la mujer del sacerdocio, se habría entablado una relación con la obra de arte sustancialmente distinta a la de los conventos de las respectivas órdenes masculinas, en los que no eran necesarias compensaciones de este tipo. Pero implicaría también en último término que en el contexto de los conventos femeninos se darían motivos figurativos específicos que reaccionarían o se ajustarían particularmente a la piedad de impronta visual-visionaria de las monjas ${ }^{6}$.

${ }^{3} \mathrm{Al}$ respecto C. Jäggi, Frauenklöster im Spätmittelalter, pp. 247 y ss.

${ }^{4}$ C. Bruzelius, Hearing is Believing; S. Romano, Gli affreschi di S. Pietro in vineis.

5 T. Lentes, Bild, Reform und Cura monialium, p. 191 ("war das Bild Sakrament, Ort der Begegnung mit dem Heiligen. Ihre Bildandacht wäre somit die Fortführung kirchlich-sakramentalen Handelns, zu der den Nonnen der Zugang verschlossen blieb. (...) Das Votivgebet der Nonnen, ob nun am äußeren Bild oder mittels der Imagination, wurde zu einer Analogie des Messopfers im Mittelalter").

${ }^{6}$ Ibidem, p. 191. 
Es obvia, en este éste contexto, la referencia a tipos iconográficos tales como Maria gravida, la figura del niño Jesús junto a su cuna y, no en último lugar, el grupo de Cristo y Juan (fig. 3) que parecen hallar en los conventos de mujeres su máxima difusión ${ }^{7}$. Sin embargo, querer limitar el patrimonio artístico de los conventos femeninos a estos ámbitos temáticos significaría apartar la mirada a priori de la gran variedad de obras allí reunidas. En realidad hasta ahora apenas se ha estudiado de manera sistemática cuándo, dónde, de qué manera y con qué propósito o finalidad las monjas entraban en contacto con las obras conservadas en sus conventos ${ }^{8}$. ¿Existían unos temas o esquemas figurativos que las monjas preferían a otros? Y si así era ¿en qué contexto funcional? ¿Volvían realmente las monjas la mirada durante el sacrificio de la misa hacia las obras de arte figurativas y compensaban con ello la no visibilidad de aquello que acontecía en el altar? ¿O jugaban las imágenes, en primer término, el papel de estímulo durante los "ejercicios místicos de meditación" como sostiene sobre todo la investigación relacionada con la mística ${ }^{9}$ ¿Cómo y con qué función iban las obras de arte a parar a los conventos y cómo fueron, con el tiempo, usadas e incluso reinterpretadas? ${ }^{10}$. Y finalmente ¿hay en los conventos femeninos de la Edad Media tardía indicios de prácticas religiosas relativas a las imágenes diversas de las llevadas a cabo por la misma época en los conventos masculinos?

\section{LOS LIBROS DE MONJAS DE TEUTONIA COMO FUENTE}

Las mejores fuentes, aquellas que ofrecen las respuestas más ricas a estos interrogantes, son los llamados Libros de monjas, es decir, colecciones de biografías de monjas particulares, famosas por haber recibido una gracia especial. Se han conservado un total de nueve de estos Libros de monjas: todos ellos proceden de conventos de Teutonia, es decir, de la antigua provincia dominica alto alemana de la que formaban parte Alsacia y las actuales

\footnotetext{
${ }^{7}$ Una buena visión de conjunto sobre las obras de arte en los conventos de mujeres la ofrece el catálogo de la exposición Krone und Schleier. Kunst aus mittelalterlichen Frauenklöstern.

8 Otros estudios llevados a cabo en este ámbito temático en J.F. Hamburger, Nuns as Artists y J.F. Hamburger, The Visual and the Visionary. Véase también C. Jäggi, "Sy bettet och gewonlich vor únser frowen bild..." Überlegungen zur Funktion; B. Boerner, Le rôle de l'image sculptée; J.F. Hamburger et al. (eds), Frauen - Kloster - Kunst.

9 E. Benz, Christliche Mystik und christliche Kunst; W. Blank, Dominikanische Frauenmystik; R. Haussherr, Über die Christus-Johannes-Gruppen; E. Vavra, Bildmotivik und Frauenmystik.

${ }^{10}$ Véase al respecto C. Jäggi, Wie kam Kunst ins Kloster?
} 
Suiza del norte y Alemania meridional ${ }^{11}$. Sus primeros esbozos se remontan al siglo XIV, sobre todo a la primera mitad, pero casi nunca nos han llegado en copias de la época sino sólo en redacciones más recientes, en la mayor parte de los casos fechables en el siglo XV y producidas en el marco de la reforma monástica llevada a cabo por entonces en muchos conventos de mujeres con el objetivo de regresar a los antiguos ideales de la Orden. A partir de esta dificultad, se ha desarrollado en la investigación una controversia en torno a la cuestión de hasta qué punto estos Libros de monjas pueden considerarse fuentes del siglo XIV y deben de ser tomados en serio. Yo personalmente estoy de acuerdo con los historiadores, en particular con Peter Dinzelbacher, quien ya en 1988 se expresó con vehemencia en contra de la tendencia de la germanística alemana a considerar que las Vidas de las monjas solo podían ser valoradas como escritos didácticos tópicamente elaborados y privados por tanto de cualquier tipo de credibilidad en relación a los procesos descritos en ellas $^{12}$. Dinzelbacher fundó su defensa sobre las narraciones de experiencias místicas y visionarias exclusivamente, pero también en el caso de las citadas obras de arte materiales no hay razón para dudar que -al menos en el momento de la formación de la Vida o colección de Vidas- éstas estuvieran realmente presentes en los respectivos conventos y que las monjas entraran en contacto con ellas en la manera descrita. Si las experiencias de gracia tenían que parecerles plausibles a un público contemporáneo que era, en el caso de las Vidas de monjas, el propio convento - cosa que pretendía con toda seguridad el autor o autora de las mismas-, al menos las indicaciones sobre parámetros externos, es decir, la colocación espacial de estas experiencias místicas, no podían ser reconocibles como mera ficción literaria. Por otro lado, no es en absoluto importante si las noticias allí recogidas son para cada caso concreto "auténticas" o "falsas"; incluso si hubieran sido inventadas o compiladas de fuentes más antiguas, justamente por la suscitada necesidad de plausibilidad, aportarían datos representativos acerca de las expectativas y comportamientos de la época en relación con las imágenes ${ }^{13}$.

${ }^{11}$ Recopilados por S. Ringler, Quellen und Studien zur Viten- und Offenbarungsliteratur; G. Lewis, By Women, for Women, about Women .

${ }^{12}$ P. Dinzelbacher, Zur Interpretation erlebnismystischer Texte des Mittelalters. La posición contraria está representada por S. Ringler, Quellen und Studien zur Viten- und Offenbarungsliteratur, pp. 8-15; S. Bürkle, Literatur im Kloster, pp. 5 y ss., 25, 33 y ss., 53; D. Vassilevitch, "Schrei der Seele" oder didaktische Stilisierung?

${ }^{13}$ J. F. Hamburger, Art, Enclosure and the Cura Monialium,p. 123. Compárese también con J.F. Hamburger, The Liber miraculorum of Unterlinden, pp. 314 y ss. 


\section{ST. KATHARINENTAL: UN CASO POR EXCELENCIA}

En base a estas consideraciones preliminares quisiera pasar ahora a ejemplos más concretos. El punto de partida será el convento de St. Katharinental, un convento de dominicas en el noreste de Suiza. De este convento nos han llegado numerosas obras de arte del siglo XIV y, en su caso, también disponemos como fuente de una serie de Vidas de monjas escritas hacia 13401350 que proporcionan pistas valiosas en relación al problema esbozado ${ }^{14}$. El convento de St. Katharinental pertenece a un conjunto de fundaciones antiguas nacidas como comunidad de mujeres devotas, al igual que Adelhausen (en Friburgo de Brisgovia, Alemania), Oetenbach (en Zúrich, Suiza), Töss (en Winterthur, Suiza), Unterlinden (en Colmar, Francia) y muchos otros conventos femeninos de Estrasburgo que en 1245 fueron encomendados o incorporados a la Orden dominica ${ }^{15}$.

En 1268-1269 la construcción de la iglesia del convento había avanzado lo bastante como para que pudiera llevarse a cabo la consagración del coro en honor a la Virgen y a san Juan Evangelista ${ }^{16}$. Pero muy pronto el edificio original presentó daños tales que se hizo necesaria una nueva construcción del coro ${ }^{17}$. Este fue consagrado en marzo de 1305 junto a cuatro altares in der

${ }^{14}$ Recientemente R. Meyer, Das "St. Katharinentaler Schwesternbuch", ha presentado una nueva edición crítica de la primera edición de A. Birlinger (Leben heiliger alemannischer). R. Meyer, Das "St. Katharinentaler Schwesternbuch", pp. 23-41, diferencia entre un corpus básico que se produce a mediados del siglo XIV, seguramente obra de varias monjas, y una ampliación de la segunda mitad del siglo XIV y del XV.

15 K. Frei-Kundert, Zur Baugeschichte des Klosters St. Katharinental, p. 143; G. Descoeudres, Mittelalterliche Dominikanerinnenkirchen, pp. 62 y 66, n. 86; A. Knoepfli, Die Kunstdenkmäler des Kantons Thurgau, pp. 17 y ss.; R. Meyer, Das "St. Katharinentaler Schwesternbuch”, pp. 144 y ss.; E. Eugster, St. Katharinental, p. 783. Para las incorporaciones de 1245 , en general, I. Grübel, Bettelorden und Frauenfrömmigkeit im 13. Jahrhundert, p. 64; más recientemente P. Zimmer, Die Dominikaner und Dominikanerinnen in der Schweiz, pp. 42 y ss.

16 R. Meyer, Das "St. Katharinentaler Schwesternbuch", p. 145 ("Do dis alles geschehen was, do fvogte vns got ein grosse gelvke, das der hohe lerer vnd der wirdich bischoffe Albreht her ze vns kome, der ein liehte was der cristenheit vnd ein brvoder predier ordens. Der wihte vns vnd wihte den vron alter vnd den chore indie ere vnser vrown, der werdvn kvneginne von himelriche, vnd des gvoten sant Johannes ewanglista") Compárese con el documento del 2 de septiembre de 1267 en el que se hace referencia a la inmediata consagración de la anterior iglesia ("ecclesiam (...) in proximo facere dedicari"); Thurgauisches Urkundenbuch, vol. III, pp. 335 y ss., $n^{\circ}$ 524. En la nave se consagraron en esa misma ocasión también dos altares, uno dedicado a san Nicolás y santa Catalina y el otro a los dos santos dominicos, Domingo y Pedro Mártir; R. Meyer, Das “St. Katharinentaler Schwesternbuch”, p. 145.

${ }^{17}$ Según la "Historia de la fundación" (Liber fundacionis) incorporada en el "libro de monjas" el primitivo coro amenazaba "con derruirse de uno de los lados" ("ze einer sittvn gevallen sin"), pero antes dice que Eberhard de Kreuzlingen se había apiadado de las hermanas porque en la primera construcción no podían ver la elevación de la Ostia ("wan wir vnsern herren ze enheiner messe niemer sehen gesahen"). R. Meyer, Das "St. Katharinentaler Schwesternbuch", p. 145. Además según informa el Liber fundacionis, el convento había crecido en los primeros 
kilchun, es decir, en la nave ${ }^{18}$. Desgraciadamente hoy no quedan restos de esta construcción medieval, porque la iglesia y el convento sufrieron en 1715-1734 una reconstrucción barroca ${ }^{19}$. El convento como tal, tras haber sido disuelto por poco tiempo una primera vez a consecuencia de la Reforma, reabriéndose poco después, fue definitivamente abolido en 1869; desde entonces los edificios del antiguo monasterio se han destinado a fines profanos y, restaurados en los años setenta, albergan desde 1996 la clínica Katharinental de la región de Thurgau.

A falta de prospecciones arqueológicas, para la reconstrucción de la iglesia del convento medieval solo se puede recurrir a las fuentes escritas o figurativas así como a consideraciones relacionadas con la tipología arquitectónica. Imágenes conservadas de la época inmediatamente anterior a la restauración barroca, documentan en la zona de la iglesia un largo edificio rectangular sobre el que se levantaba en medio una linterna (fig. 1), una tipología que se encuentra también en otras iglesias dominicas de los siglos XIII y XIV en la Suiza nororiental como las de Töss, Oetenbach o Schwyz ${ }^{20}$. Como en éstas, también para el caso de St. Katharinental, puede inferirse que la iglesia conventual se encontraba dividida en dos espacios contiguos; por la localización de los altares que indica el mencionado documento de consagración de 1305 , se deduce que el espacio oriental servía de coro a las monjas y por tanto formaba parte de la clausura, mientras que el occidental parece corresponderse con el espacio destinado a laicos, y servía, en tanto que tal, de lugar de culto a conversos y benefactores que, como veremos, residían en número no desdeñable junto al convento ${ }^{21}$. Entre los dos espacios se alzaba un coro alto, bajo

años cuarenta aumentando el número de monjas de 40 a 150; R. Meyer, Das "St. Katharinentaler Schwesternbuch", p. 148.

${ }^{18}$ Thurgauisches Urkundenbuch, vol. IV, pp. 130 y ss., $\mathrm{n}^{\circ} 1057$ (año 1305): Johannes, "Episcopus Salvinensis", dio a conocer en este documento que él "den vrovwen bi Diezenhoven, ze dem kloster Predier ordens, gewihet (habe) den kore in Unser Vrovwen ere und in sant Johannes Ewangelista ere. Und habin gewihet drie alter in der kilchun und ain uf der kanzel. Den altar in der kilchun in dem winchel gen dem kloster (...) in Unser Vrovwn ere und in sant Johannes Ewangelista ere, sant Peters des prediers, sant Jacob dez grozen und sant Mariun Magdalenun. (...) Den mitteln altar (...) in Unser Vrown ere und sant Dominicus und sant Johannes Baptista. (...) Den altar bi dem venster gen dem berge (..) in Unser Vrovwn ere und sant Katherinun und sant Nicholas, sant Agathun und sant Thoman de Kantelberch. (...). Den altar uf der Kanzel. (...) in Unser Vrown ere und aller engel und aller hailigen”. Véase también el pasaje correspondiente en Liber fundacionis; R. Meyer, Das "St. Katharinentaler Schwesternbuch", pp. 145 y ss.

19 Sobre la historia de la construcción del establecimiento en época moderna véase A. Knoepfli, Die Kunstdenkmäler des Kantons Thurgau, pp. 19-22 y 31-36.

20 Ibidem, p. 29 Abb. 13 y 14. En lo referente al tipo constructivo véanse G. Descoeudres, Mittelalterliche Dominikanerinnenkirchen, y C. Jäggi, Frauenklöster im Spätmittelalter, pp. 54 y ss.

${ }^{21}$ Véase nota 18. Sobre la distribución interior de la iglesia conventual de St. Katharinental véase G. Descoeudres, Mittelalterliche Dominikanerinnenkirchen, pp. 61-65; P. Zimmer, Die Funktion und Ausstattung des Altares auf der Nonnenempore, pp. 79-82; C. Jäggi, Frauenklöster im Spätmittelalter, pp. 55-57 y 207 y ss. 
cuyos arcos abiertos hacia el oeste se encontraban tres de los altares, consagrados junto con el nuevo coro en 1305, formando así un verdadero presbiterio de la iglesia exterior, es decir, la de los laicos. En el centro de la pared posterior del coro alto, se había colocado una ventana enrejada, a través de la que las monjas reunidas en el coro podían ver la elevación de la ostia cuando el capellán celebraba la misa conventual sobre el altar central del coro alto los días laborales y los domingos normales ${ }^{22}$. En cambio, en las festividades solemnes en las que se impartía también la comunión, los sacerdotes, al igual que en los otros conventos de dominicas, también en St. Katharinental entraban en la clausura para celebrar la misa sobre el altar mayor del coro de las monjas ${ }^{23}$.

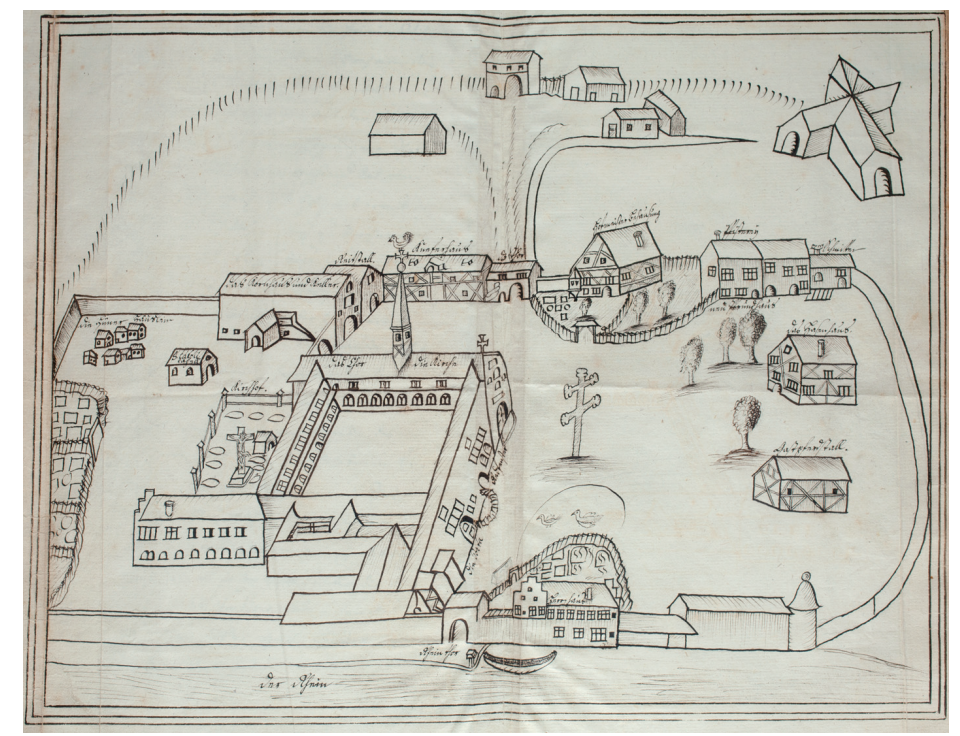

Fig. 1. St. Katharinental, antiguo convento de dominicas, vista desde el norte, copia de un dibujo de 1623. Kantonsbibliothek Frauenfeld, Ms. Y 204. Foto: Kantonsbibliothek Frauenfeld.

${ }^{22}$ En el Liber Fundacionis se dice que fue donación de Eberhard de Kreuzlingen: "Der machet vns die kanzelle vnd die vier alter (...). Vnd der mittel alter, da er das venster hat gemachet, da wir vnsern herren sehen, der ist gewihet in vnser vrown ere vnd sant Johannes baptist vnd sant Dominicus"; R. Meyer, Das "St. Katharinentaler Schwesternbuch", p. 145.

${ }^{23}$ No nos ha llegado información acerca de la disposición del altar mayor de St. Katharinental, pero a partir de los hallazgos arqueológicos de la iglesia de las dominicas de Schwyzer, asi como de la de las cistercienses de Schweizer podemos contar con que se hallaba en la parte este; G. Descoeudres, Mittelalterliche Dominikanerinnenkirchen, p. 43; Zisterzienserbauten in der Schweiz, passim; C. Jäggi, Frauenklöster im Spätmittelalter, p. 208. P. Zimmer, Die Funktion und Ausstattung des Altares auf der Nonnenempore, p. 87. 
Si se ha de prestar fe a la historia de la fundación del convento escrita en el siglo $\mathrm{XIV}^{24}$, la iglesia y los restantes edificios del monasterio debieron su existencia a la generosidad de numerosos benefactores. La nueva construcción del coro de 1305, incluidos el coro alto y los cuatro nuevos altares, fue financiada por Eberhardt, un ciudadano de Kreuzlingen, quien junto con el dinero también suministró sillares de piedra tallada para las ventanas, mientras que los canónigos agustinianos de Kreuzlingen debieron de enviar a St. Katharinental una gran cantidad de tugstein (tufo) a través del lago de Constanza y del $\operatorname{Rin}^{25}$. Un caballero de Salenstein y su mujer hicieron construir una casa donde ahora se encuentran los hermanos, lo que significa probablemente la casa de los conversos ${ }^{26}$. Una historia parecida nos la transmiten Burkhard de Tannheim y su mujer que tenían no menos de cinco hijas viviendo en St. Katharinental: ambos bvwet vnd sasen indem hvse, da mine herren die predier vnd vnse capplan inne ist, es decir, construyeron (y por lo visto también la habitaron) la casa en la que vivía el capellán que, aquí como en muchos otros conventos de dominicas, se encargaba de celebrar la misa cotidiana $^{27}$. En esta casa podían hospedarse también los frailes predicadores de Constanza cuando se detenían en St. Katharinental para confesar a las hermanas y administrarles la comunión. Quizá incluso vivían allí de forma estable algunos frailes, como era habitual también en otros conventos de dominicas $^{28}$.

${ }^{24}$ Para el análisis crítico-textual véase R. Meyer, Das "St. Katharinentaler Schwesternbuch", pp. 72-79.

${ }^{25}$ Véase nota 22. "ein bvorger von Costenz, der hiesse Eberhard von Cruzelingen. Der hat sin tohter in das closter getan vnd sin swester, (...) vnd och, das er zvo sim iargezit geordenet het. Der machet vns die kanzelle vnd die vier alter vnd das schoene bild vnser vrown vnd gabe vns xx marche, er vnd sin vrowe, anden chore, der wolte ze einer sittun gevallen sin. Vnd alle die grawen stein, die an den venstern sint, die sante er her ab gehowen vnd bereit"; R. Meyer, Das "St. Katharinentaler Schwesternbuch", p. 145. El regalo de los agustinos de Kreuzlingen aparece sólo en los manuscritos de finales del siglo XVII y del XVIII; A. Knoepfli, Die Kunstdenkmäler des Kantons Thurgau, p. 25.

${ }^{26}$ R. Meyer, Das "St. Katharinentaler Schwesternbuch", p. 146 ("ein ritter, der hiesse der von Salenstein. Der kam her vnd sin vrowe, vnd buweten nvd sassen in dem hvse, da nv die brvoder inne sint").

${ }^{27}$ Ibidem, p. 146.

${ }^{28}$ Ch. Folini, A. Palaia, Die Dominikanerinnenklöster Töss und St. Katharinental, p. 104. Más recientemente C. Jäggi, Frauenklöster im Spätmittelalter, pp. 190 y ss. 


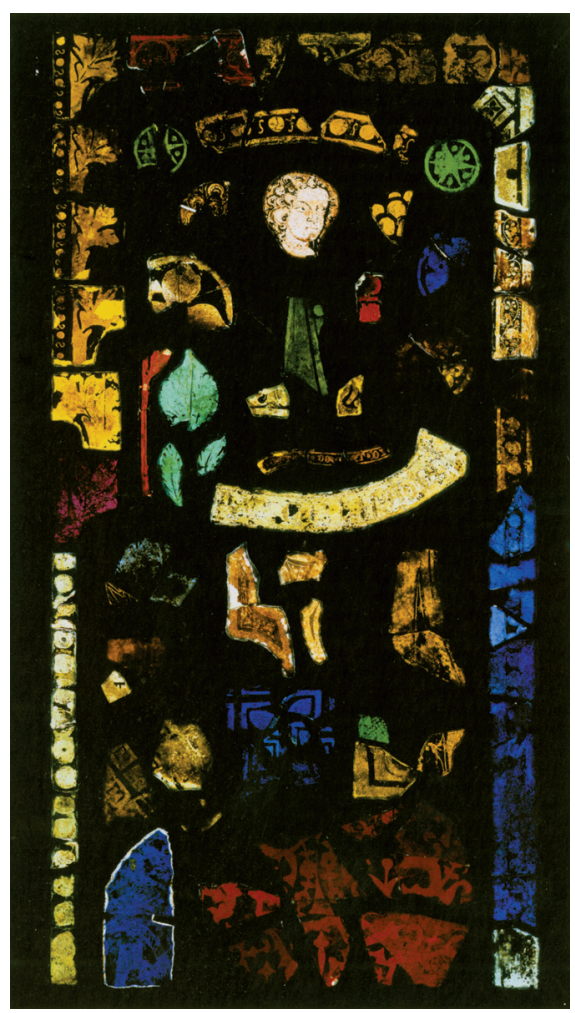

Fig. 2. Fragmentos de vidrieras de principios del siglo XIV. Frauenfeld, Historisches Museum des Kantons. Thurgau, Inv.-Nr. T23922.

Foto: Hauser y Eisenhut, St. Gallen.

Pero los mencionados cónyuges, Burkhard de Tannheim y su mujer, no financiaron solo la casa del capellán, sino que donaron también un pozo junto con un sistema de conducciones, e incluso regalaron una ventana de la iglesia, en el espacio de los laicos, cuyas vidrieras mostraban a los apóstoles Pedro y Pablo (fig. 2) ${ }^{29}$. Otra de las ventanas -la de santa Catalina y santa Inés en el coro- fue financiada por Rüdiger Heggenzi, un ciudadano de Schaffhauser que tenía asimismo dos hijas en el convento ${ }^{30}$. También

29 R. Meyer, Das "St. Katharinentaler Schwesternbuch", p. 146 ("Der machet vns den brvnnen vnd leit vns den mit sinem schaden indas closter vnd vffen die hofstat, swa man sin bedorfte. (...) Vnd galte das venster sant Peter vnd sant Paul inder kilchvn.").

${ }^{30}$ Ibidem, p. 146 ("Vnd galte das venster in dem kore sant Katherin und sant Agnes"). Hegenzzi además hizo construir una casa en la corte y donó dinero suplementario. 
dos hijas del ciudadano de Diessenhof, Martin de Stein, eran monjas en St. Katharinental; él y su mujer se mostraron tan reconocidos al convento que donaron la ventana del coro con María como mujer del apocalipsis y san Juan, y también el gran crucifijo con María y san Juan, probablemente, al igual que los restantes benefactores, a cambio por parte del convento de un numero de oraciones prescrito con exactitud ${ }^{31}$. Dada la vaguedad del redactado, no se ha podido determinar si en el caso del primero de los mencionados San Juanes se trata también de una donación de una ventana o si se debe pensar en el grupo de Christo y Juan actualmente en el museo Mayer van den Bergh de Amberes (fig. 3).

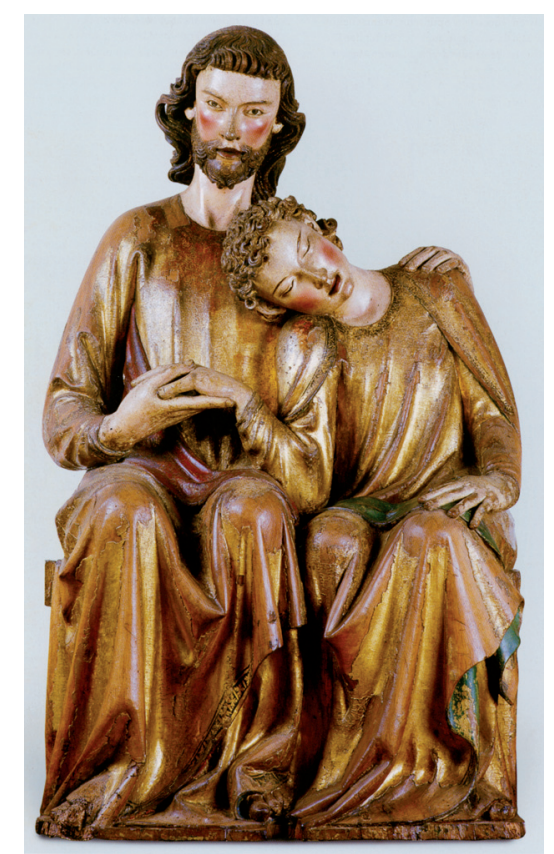

Fig. 3. Grupo de Cristo y Juan de St. Katharinental. Amberes, Museum Mayer van den Bergh, Inv.-Nr. 2094.

Foto: reproducción de la imagen de Krone und Schleier, 2005.

${ }^{31}$ Ibidem, p. 147 ("Vnd galte das venster indem kor vnser vrown mit den zwelf sternen vnd sant Johannes vnd das grosse crucifixus vnd vnser vrown vnd sant Johannes"). En matrimonio Stein dedicó además una suma de dinero para mejorar la alimentación de las monjas, tambien para el vestuatio a fin de que también las hermanas pobres recibieran mejores ropas, ("das man armen swesteran da mit ire scheffin gewant besserti"); ibidem, p. 146. 
En todo caso, está generalmente aceptado que este grupo es idéntico a la imagen de san Juan mencionada en el Liber Fundacionis que, según allí se dice, fue tallada por el maestro Heinrich escultor de Constanza, en un único tronco de nogal, tan bellamente que todos-incluido el propio maestro- se maravillaron ${ }^{32}$. Estilísticamente el grupo es fechable en los primeros años del siglo XIV, lo que permitiría poner su origen en estrecha relación con la construcción del nuevo coro de $1305^{33}$. Sus considerables dimensiones (141 x 73 x 48) dejan sospechar que no habría llegado a St. Katharinental como regalo privado de una de las monjas sino como un obsequio para todo el convento. Probablemente, la obra estaba destinada a un altar y, como tal, debía estar sobre o junto al altar mayor del coro de las monjas dedicado, además de a Nuestra Señora, al discípulo preferido de Jesús ${ }^{34}$. Del Libro de monjas de St.Katharinental solo se puede deducir que en el coro de las monjas había una imagen de san Juan de este tipo, como cuenta por ejemplo la Vida de Adelheit Pfefferhartin: rezaba en otra ocasión en el coro ante una imagen que mostraba como san Juan reposó la cabeza sobre el pecho del Señor, detrás de ella otra hermana, que también estaba orando, vio que Adelheit levitaba sobre el suelo ${ }^{35}$. Casi la misma constelación se encuentra en la Vida de Anna de Ramschwag, en la que se habla explícitamente de una gran imagen que muestra a Juan reposando en el pecho de Jesús ${ }^{36}$. Mia de Rethershofen en cambio oraba en el coro ante

32 Así cuenta el manuscrito A la historia de la fundación; K. Frei-Kundert, Zur Baugeschichte des Klosters St. Katharinental, p. 150, n. 40 ("von meister Hainnrich dem bildhauwer zu Costantz uß einem nußbom so schön gemacht (wardt), ds jedman sich verwunderte, (sogar) der meister selbst").

33 J. De Coo, Beeldhowkunst; R. Haussherr, Über die Christus-Johannes-Gruppe, pp. 81-85; A. Knoepfli, Die Kunstdenkmäler des Kantons Thurgau, pp. 231-234; P. Zimmer, Die Funktion und Ausstattung des Altares auf der Nonnenempore, pp. 92-120; V. Kaiser, Zur Funktion der Christus-Johannes-Gruppe, pp. 55 y ss.; Krone und Schleier, pp. 409-412.

${ }^{34}$ K. Frei-Kundert, Zur Baugeschichte des Klosters St. Katharinental, p. 29; R. Haussherr, Über die Christus-Johannes-Gruppe, pp. 84 y ss.; A. Knoepfli, Die Kunstdenkmäler des Kantons Thurgau, p. 233; P. Zimmer, Die Funktion und Ausstattung des Altares auf der Nonnenempore, pp. 89-93. En relación con los disturbios de la Reforma, se cuenta que la primera misa celebrada tras el regreso de la monjas al convento en 1532 tuvo lugar en el altar donde estaba la imagen de San Juan. A más tardar pues en 1601 el grupo escultótico de Cristo y Juan estaba sobre el altar del coro de las monjas; ya hacia finales del siglo XVI se documenta una romeria al altar de San Juan en el interior del coro; K. Frei-Kundert, Zur Baugeschichte des Klosters St. Katharinental, pp. 16 y 30 y ss. Después de la nueva construcción de la iglesia conventual en el siglo XVIII y de la reintroducción de la estricta clausura la imagen se destinó a la capilla de público acceso de Santa María en Einsiedeln.

35 "Si bettet ovch ze einem mal in dem kor vor dem bild, da sant Johans ruowet vff vnsers herren hertzen. Do stuond ein saeligú swester hinder ir ovch an ir gebett, dú sah, das si ob dem ertrich swebt vnd erhaben was vber das ertrich"; R. Meyer, Das "St. Katharinentaler Schwesternbuch", p. 152. En el caso de la Vida de Adelheit Pfefferhartin se trata según Meyer de un añadido de finales del siglo XIV; ibidem, pp. 42 y 295.

36 "Si bettet ze einem mal vor dem grossen bilde, da sant Johannes ruowet vff vnsers herren hertzen, vnd stuond sant Mie von Rethershouen hinder ir ovch an ir gebett vnd sah, das si als luter 
una estatua de Nuestra Señora: una vez -se dice- se hallaba en el coro absorta en oración, mientras otra hermana rezaba de rodillas ante la imagen de Nuestra Señora, Mia observó entonces una corona de oro sobre la cabeza de su compañera, y a continuación se quejo a Cristo porque a ella le había sido negado hasta entonces un tal galardón ${ }^{37}$. En otra ocasión, mientras Mia oraba frente a la imagen de María, esta le habló y le aseguró la vida eterna ${ }^{38}$. Agnes de Wangen lloraba sus penas de nuevo ante una estatua de la Madre de Dios con el niño; había entrado en el convento tras ser abandonada por su marido y ahora, al mostrar éste su arrepentimiento, dudaba de su decisión ${ }^{39}$. Como era de esperar, fue consolada por María: Nuestra Señora le puso la mano sobre la cabeza y le dijo puedes estar tranquila, jamás serás separada de mí o de mi $\mathrm{Hijo}^{40}$. El marido de Agnes se convirtió en capellán de St. Katharinental y vivió allí hasta su muerte. Algo parecido sucedió en el caso de Adelheit Othwins que acudió ante una imagen de María, que mostraba a Nuestra Señora con el niño en su regazo, y le rogó a María que hiciera entrar en razón a su hermano que había abandonado la Orden sanjuanista; mientras estaba orando, Cristo niño le acercó el piececito

que ella tomó en su mano. Entonces el piececito se convirtió en carne y sangre y el niño lo retiro. Entonces ella (Adelheit) rogo a Nuestra Señora y dijo: Madre de Misericordia, yo te pregunto, dime si no te he prestado jamás servicio como para que puedas asistirme ahora en mi turbación. Entonces la Madre de Dios dijo: Nunca más abandonaré a tu hermano ${ }^{41}$.

ward als ein cristalle vnd das reht ein schin eins liehtes von in gie. Das sah si all die wil, do si bettet vor dem bild"; R. Meyer, Das "St. Katharinentaler Schwesternbuch", p. 130. Para la pertenencia de la Vida de Anna de Ramschwag al corpus original de mediados del siglo XIV: ibidem, p. 26.

37 "Die (= Mia, C. J.) was ze einem mal in dem kor an ir gebett, vnd ein andrú swester knúwet ovch da an ir gebett vor vnser frowen bild"; R. Meyer, Das "St. Katharinentaler Schwesternbuch", pp. 117 y ss. La Vida de Mia de Rechtershofen pertenece al corpus original de mediados del siglo XIV; ibidem, p. 25.

${ }^{38}$ R. Meyer, Das "St. Katharinentaler Schwesternbuch", p. 118 (“do redt vnser frow mit ir vnd sichert si des ewigen lebens").

39 "Ein swester dú hiess Angnes von Wangen, die schied sich von ir wirt vnd kam in vnser closter. Darnach gerow es ir wirt, das er si hat vff geben, vnd da von ward si von hertzen betruebt. Vnd gieng fúr vnser frowen bild vnd klagt ir vnd ir kind die betruebt ir hertzen. Do leit ir vnsa frow die hant vff das hovbt vnd trost si vnd sprach: «Du solt sicher sin, das dv von minem kind vnd von mir niemer wirst gescheiden.» Darnach kam er vff vnser hoffstatt vnd ward vnser caplan vnd lebt gar tugentlich vntz an sin end"; R. Meyer, Das "St. Katharinentaler Schwesternbuch", p. 123. También esta Vida pertenece al corpus original de mediados del siglo XIV; ibidem, p. 25.

40 Véase n. 37.

41 "Ein swester dú hiess swester Adelheit Oethwins. Di hatt einen bruoder in spitaler orden, der gieng vss dem orden. Da von ward si gar hertzklich betruebt vnd bettet vnser frowen gross gebett, das si ir hulffe, das er wider in den orden kaeme. Vnd ze einem mal do gieng si fúr vnser frowen bild, da si das kindli vff der schoss hat, vnd batt vnser frowen mit hertzklicher begird, das si si erfrowti an ir geswistergit. Vnd in dem gebett do bot ir das kindli sin fuessli, das nam si in ir hand. Do ward 
En este último caso parece haberse tratado de una Virgen en trono. La imagen de María que tiene en brazos a Nuestro Señor ${ }^{42}$, mencionada en la otra Vida, debía tratarse en cambio de una figura en pie, a propósito de la cual es natural remitirse a la talla de madera policromada de María en pie con el niño que todavía hoy se encuentra en la iglesia de St. Katharinental, si bien retocada en una reelaboración barroca (fig. 4$)^{43}$.

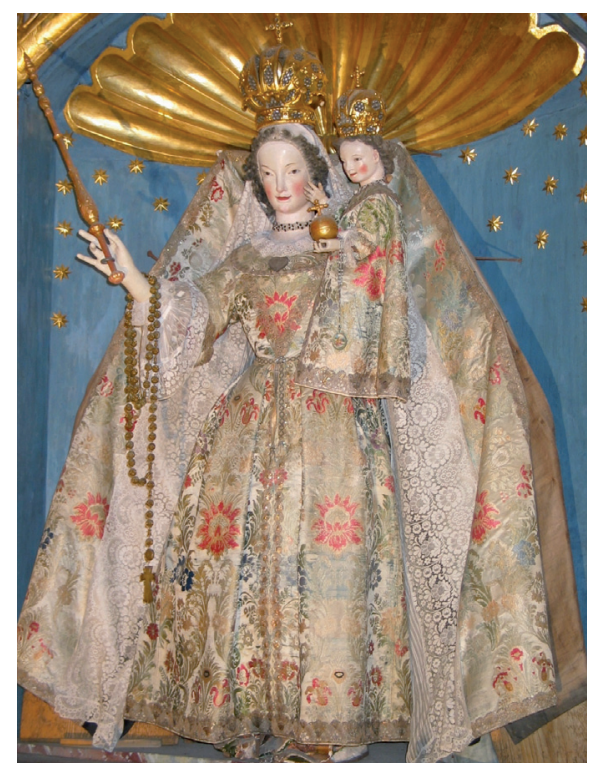

Fig. 4. Estatua de la Virgen con el Niño, 1300-1305, retocada en1745 como Madonna vestida barroca. St. Katharinental, antiguo monasterio. Foto: C. Jaggi.

das fuessli flaisch und bluot. Vnd do zoh das kindli sin fuessli an sich. Do ermanet si vnser frowen vnd sprach: «Ach, muoter aller erbarmhertzkeit, jch ermanen dich, ob ich dir ie keinen dienst getet, das du mich erfroewest jn miner hertzklichen betruebt». Do sprach vnser frow: «Du solt wissen, daz ich dinen bruoder niemer wil gelassen»"; R. Meyer, Das "St. Katharinentaler Schwesternbuch", pp. 139 y ss. Perteneciente al corpus original de mediados del siglo XIV; ibidem, p. 25.

42 "Ein swester dú hiess swester Anne von Costentz. Die gieng fúr vnser frowen bild, da si vnsern herren an ir arm het, vnd nam des kindlis fuessli in ir hand mit grosser andaht. Do ward das fuessli fleisch und bluot in ir hant"; R. Meyer, Das "St. Katharinentaler Schwesternbuch", p. 107. Perteneciente al corpus original de mediados del siglo XIV; ibidem, p. 25.

${ }^{43}$ La estatua de $121 \mathrm{~cm}$ de alto, tallada no en nogal como ambas imágenes de Juan sino en madera de roble, fue transformada en 1732 o 1745 en una Virgen con ropajes y pintada con un nuevo acabado. Desde 1979 ha sido restaurada poniendo al descubierto su aspecto original; A. Knoepfli, Die Kunstdenkmäler des Kantons Thurgau, pp. 234-236; Krone und Schleier, pp. 411-413. En el registro de sacristía de 1589 se mencionan tres imágenes de María: "Unsere liebe Frau im Winkel", una de las cuales probablemente estaba en el altar del norte bajo el coro alto (véase los Weiheurkunde de 1305, n. 18), además "Unser l. frow von Creuzlingen" y "Unser lieben Frau von Strassburg"; K. Frei-Kundert, Zur Baugeschichte des Klosters St. Katharinental, pp. 36 y 153. 
En base a consideraciones estilísticas esta talla puede adscribirse al mismo taller de Constanza que el grupo de Cristo y Juan y pertenecería junto con este al mobiliario del nuevo edificio de 1305, lo que sufragaría la hipótesis de que esta talla se habría hallado, por decirlo así, asociada a dicho grupo y habría estado emplazada, junto con él, sobre el altar del coro de las monjas; quizá es ella das schoene bild vnser vrown (la bella imagen de Nuestra Señora) que aparece en el Liber Fundacionis entre los ricos regalos de Eberhards de Kreuzlingen ${ }^{44}$. Al círculo del taller de Heinrich en Constanza han de atribuirse también la preciosa talla de madera de San Juan Bautista (fig. 5) que se encuentra hoy en el Badischen Landesmuseum de Karlsruhe ${ }^{45}$, así como la figura en madera de Santo Domingo (fig. 6) lamentablemente despojada de su acabado, hoy en el convento de dominicas de Maria Zuflucht en Weesen ${ }^{46}$. Ninguna de las dos, sin embargo, es citada en las Vidas de las monjas, lo que podría derivarse del hecho de encontrarse ambas en la iglesia exterior, es decir, en el espacio de los laicos y por tanto invisibles para las monjas. Quizá adornaban el altar central del coro alto, que estaba dedicado además de a María, a San Juan y a Santo Domingo ${ }^{47}$. Por el contrario se menciona varias veces un crucifijo. Elsbeth de Stoffeln, en una etapa de profundas preocupaciones -era ecónoma y sufría el mobbing de sus hermanas de comunidad- tomó una tabla en su mano con la imagen de un crucifijo y de Nuestra Señora de los dolores y les confió sus penas a ambos: Entonces habló María: ¿Quieres ser recompensada por la gente? ;Yo y mi hijo seremos tu recompensa eterna! Y con ello cesaron sus penas ${ }^{48}$.

${ }^{44}$ Véase n. 25.

45 Madera de nogal; alto: $179 \mathrm{~cm}$, ancho: $51 \mathrm{~cm}$; exactamente del Musée des Arts décoratifs in Paris, y desde 1984 como depósito de intercambio en el Badischen Landesmuseum de Karlsruhe; A. Knoepfli, Die Kunstdenkmäler des Kantons Thurgau, pp. 226-228; Krone und Schleier, p. 409

${ }^{46}$ De $75 \mathrm{~cm}$ de altura, la figura es claramente más pequeña que las otras, además está hecha -como la mencionada figura de María - en madera de roble; sobre su cabeza había una cavidad de $8 \mathrm{~cm}$. de profundidad en la que probablemente se había insertado una reliquia; A. Knoepfli, Die Kunstdenkmäler des Kantons Thurgau, pp. 228 y ss.; Krone und Schleier, p. 413.

47 Véase los Weiheurkunde de 1305 y el Liber fundacionis; véase más arriba n. 18; P. Zimmer, Die Funktion und Ausstattung des Altares auf der Nonnenempore, pp. 90s. En el claustro había además una imagen pintada "gemohltes bildnuss" de Juan Bautista; véase más abajo n. 102 .

48 "Disú swester was ze einer zit in sunderlicher betruebt. Do was si schaffnerin vnd dunkt si, das man etwenn nit wol von ir verguot hette, das sie doch durch guot tett. Vnd nam ein tauell fúr si, da was ein crucifixus an vnd vnser frow vnder dem crútz, vnd klegt in ir betruebt. Do sprach vnser frow: «Wilt du lon empfahen von den lúten? Jch vnd min kind wend doch din ewiger lon sin!» Mit dem wort do was ein end aller ir betruebt..."; R. Meyer, "Das St. Katharinentaler Schwesternbuch", p. 119; sobre la pertenencia de esta Vida al corpus original de mediados del siglo XIV ver ibidem, p. 25. Seguramente se trata de una pequeña tabla pintada del tipo de los "altarcillos privados" del convento de clarisas de Köln; véase C. Jäggi, Frauenklöster im Spätmittelalter, pp. 304-309. 


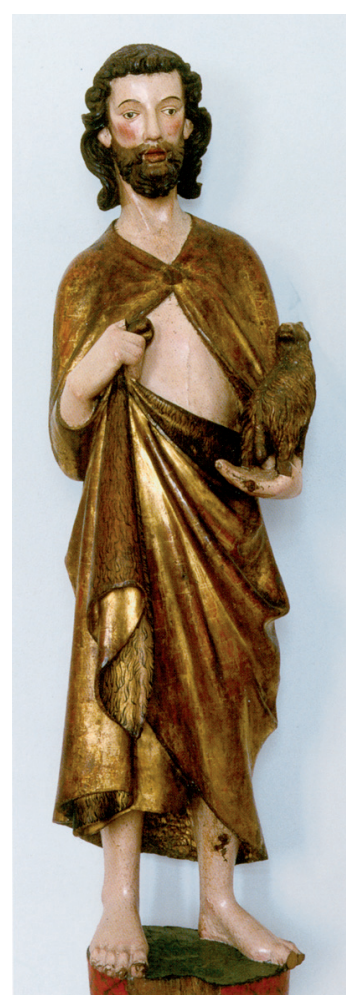

Fig. 5. Figura de pie de Juan el Bautista, 1300. Karlsruhe, Badisches Landesmuseum, Inv.-Nr. L10; préstamo permanente del Musée des Arts Décoratifs, París, inv PE 484. Foto: Bad. Landesmuseum Karlsruhe.

Otra monja, Richmut de Winterthur, estando enferma, recorría una vez después de maitines el claustro y, cuando llegó al portón, se inclinó ante el crucifijo allí colgado y se lamentó a Cristo de sus dolores, por lo que éste le consoló recordándole su propio sufrimiento ${ }^{49}$. Se trataba probablemente de la misma cruz ante la que también Adelheit Othwins se arrodilló una mañana cuando se dirigía al Capítulo. Dice el texto que Adelheit una vez, después de Pascua, al acabar

\footnotetext{
49 "Ein swester dú hiess Richmuot von Winterthur. Die was ze einem mal gar siech vnd hat ovch liden an dem hertzen. Die gieng nach einer metti vmb den crútzgang vnd do si fúr die port kam, do neig si einem crucifixus, das da ist, vnd sprach: «Ach herr, wie ist mir so we an lib vnd an hertzen!» Do redte vnser herr mit ir ab dem crútz vnd sprach: «Weistv nit, das Cristus, gottes sun, nit wider mohte komen in sin eigen rich won mit liden?»"; R. Meyer, Das "St. Katharinentaler Schwesternbuch", p. 98. También esta Vida pertenece al corpus original de mediados del siglo XIV; ibidem, p. 24.
} 
maitines oraba con gran devoción. Y cuando habían tocado prima, dejó el coro yllegó ante la sala capitular dónde se arrodillóante un crucifijo, después se alzó y entró en la sala capitular donde había otro crucifijo ${ }^{50}$. Ante esa misma cruz que pendía en la sala capitular debió de rezar también Hedwig de Unlegellen, una hermana lega, y súbitamente el Crucificado le habló desde la cruz, le perdonó todos sus pecados y le aseguró la vida eterna ${ }^{51}$. Otra cruz más estaba colgada en el dormitorio: en la Vida de Mechtild de Wangen se explica que el crucifijo había hablado con esta santa hermana y le había perdonado todos sus pecados $^{52}$. No es posible, en cambio, localizar con mayor precisión el crucifijo al que Anna de Stoffeln rogó por la sanación de su hermana Mechtild, ni tampoco aquel del que Adelheit de Geilingen quiso saber qué le podía pedir y él le aconsejó que le pidiera el perdón de todos sus pecados ${ }^{53}$. Cruces sin localización espacial son también mencionadas en la Vida de Gertrud de Herblingen quien recitába después de completas su oración penitencial (Confiteor) ante un crucifijo, o en la de Adelheit de Stein que imploró la liberación de su posesión por el demonio ${ }^{54}$. También sin localización espacial se encuentra el

50 "Disú saelig swester hat ze einer zit nach den ostran nah einer metti andëhtiklich gebettet. Vnd do prim zit ward, do gieng si vss dem kor fúr das capitel vnd knúwet da nider fúr das crucifixus. Vnd do si vff sach, do dunkt si, das si vnser herr meindi. Do ging si in das capitel fúr das crucifixus vnd sach, daz vnser herr ein kron hat an dem rechten arme...”; R. Meyer, Das "Das St. Katharinentaler Schwesternbuch", p. 140. Sobre la pertenencia de la Vida de Adelheit Othwins al corpus original véase ibidem, p. 26.

51 "Ein schwester die hiess swester Haedwig von Vnlegellen vnd was ein lay schwester. Die bettet ze einem mal vor dem crútz, das in dem capittel ist. Do ret vnser herr mit ir ab dem crútz vnd vergab ir all ir súnd vnd sichert si des ewigen lebens”; R. Meyer, Das "Das St. Katharinentaler Schwesternbuch",p. 102. Perteneciente al corpus original de mediados del siglo XIV; ibidem, p. 24.

52 "Ein swester dú hiess sant Maehthilt von Wangen, mit der redt das crucifixus, das in dem grossen dormiter ist, vnd vergab ir all ir súnd"; R. Meyer, Das "Das St. Katharinentaler Schwesternbuch", p. 122. Sobre la pertenencia de esta Vida al corpus original véase ibidem, p. 25.

53 "Ein swester dú hiess sant Anne von Stoffeln. Die was gar eins milten hertzen gen armen lúten vnd tett sant Mehthilt gar guetlich. Vnd ze einem mal do gelag si gar vngenislich, das wir wanden, das sy niemer moeht genesen. Do gieng disú swester an ir gebett vnd strakt sich an ir langen venie fúr ein crucifixus vnd batt vnsern herren mit grossem ernst, das er die swester fristi langer ze leben..."; R. Meyer, Das “Das St. Katharinentaler Schwesternbuch", p. 136. "Ein swester dú hiess sant Adelheit von Geilingen. Die bettet ze einem mal vor einem crucifixus vnd sprach zuo vnserm herren: «Herr, jch ermanen dich aller diner erbermd, das dv mich lerest, was ich dich bitten soelle». Do sprach ein stimm: «Das ist, das dv mich bitten solt, das ich dir all din svnd vergeb...»"; ibidem, p. 139. Acerca de la pertenencia de ambas Vidas al corpus original véase ibidem, p. 26.

54 "Ein swester dú hiess sant Gerdrut von Herblingen. Do die eins tages an ir gebett was nach der complet vor einem crucifixus, do sprach si vnserm herren ir «Confiteor». Do ledget vnser herr den rehten arm ab dem crútz vnd lait ir sin hand vff ir hovpt vnd vergab ir alle ir súnd"; R. Meyer, Das "Das St. Katharinentaler Schwesternbuch", p. 115. "Ein swester dú hiess sant Adelheit von Stein. Die hat ze einer zit grosses liden an dem hertzen. Vnd in dem liden wart si von dem túfel vberwunden, das sie gedaht ze tuenne dú ding, die wider got sind. Vnd in disem ding do gie si fúr ein crucifixus vnd bettet. Do sah si, das vnserm herren all sin wunden bluotent"; ibidem, p. 137. Ambas Vidas pertenecen al corpus original de mediados del siglo XIV; ibidem, pp. 25 y ss. 
gran crucifijo que se inclinó hacia otra de las monjas llamada Adelheit, cuando estaba ante él con dos hermanas más, y le abrazó pronunciando la palabra Avete!, usando con ella el saludo que -así lo explica el Libro de monjas- había dirigido a las tres mujeres, cuando se les apareció tras su resurrección ${ }^{55}$. Todas estas cruces debían encontrarse en el ámbito de la clausura. En el caso del gran crucifijo se puede además deducir que no podía estar colgado demasiado alto, por lo que difícilmente puede pensarse en la cruz triunfal, es decir, en aquella flanqueada por las figuras de María y Juan que tenía su origen en una donación de Martin de Stein $^{56}$.

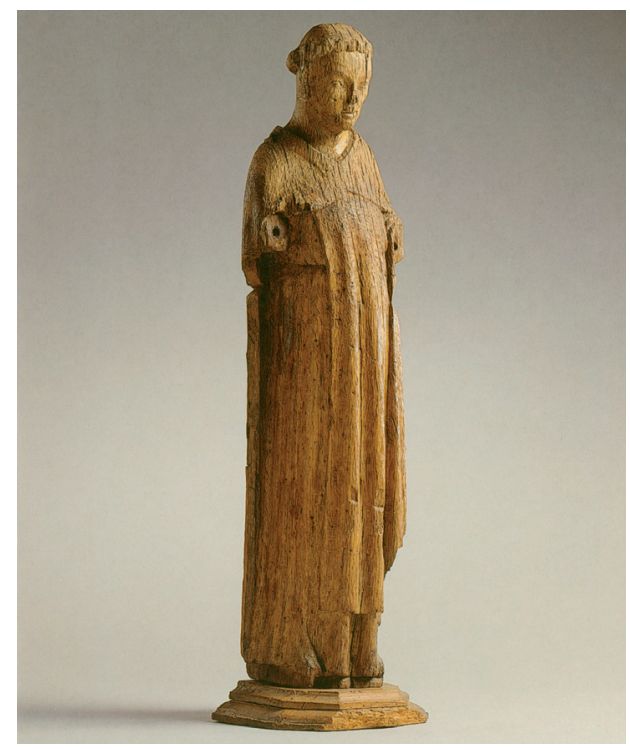

Fig. 6. Estatua de madera de Santo Domingo, 1300/1305. Weesen, Monasterio de dominicas Maria Zuflucht. Foto: Erismann y Gessler, Amlikon

55 "Ein swester dú hiess swester Adelheit dú Huoterin vnd was priorin. Der was ze einem male vor, wie si vnd noch zwv swestran stuenden vor vnserm grossen crucifixus. Vnd sprach vnser herr zuo in: 〈Auete!〉, das wort, das er zuo den drin frowen sprach, do er in erschein nach siner vrstendi"; R. Meyer, Das "Das St. Katharinentaler Schwesternbuch", p. 135. También la Vida de Adelheit "der Huterin" pertenece al corpus original; ibidem, p. 24.

${ }^{56}$ La cruz triunfal, que incluía flanqueándola las figuras de María y Juan, debe de tener su origen en una donación de Martin de Stein, por esta razón queda en cualquier caso excluida; véase más arriba n. 32. Al respecto también K. Frei-Kundert, Zur Baugeschichte des Klosters St. Katharinental, p. 25 y P. Zimmer, Die Funktion und Ausstattung des Altars auf der Nonnenempore, p. 91. 
Quizá con el gran crucifijo se está haciendo referencia a la cruz de madera monumental que todavía hoy se conserva en la iglesia conventual de St. Katharinental (figs. 7 y 8) en el pilar del crucero sudoccidental y que -al igual que el grupo de Cristo y Juan, la estatua de María con el niño y las figuras de Juan Bautista y Santo Domingo- ha de proceder hacia 1300 del taller del maestro Heinrich en Constanza. Este crucifijo, en el que el cuerpo de Cristo mide 2,63m, es claramente mayor que el del llamado Maestro de Liebenfels, de una generación más tarde, en los años treinta, cuyo cuerpo solo mide $77 \mathrm{~cm}^{57}$. Especialmente valiosa es la cruz de mesa pintada por los dos lados (fig. 9), hoy en el Historisches Museum de Basel, que procede asimismo de St. Katharinental ${ }^{58}$. Realizada poco después de mediados del siglo XIII, debió de haber formado parte del primer mobiliario del convento; sus aplicaciones en forma de perlas que imitan metales nobles, pero también la pintura de los dos lados, indican claramente que se trata de una cruz de altar que en ocasiones especiales, por ejemplo el Viernes Santo o durante las procesiones fúnebres por el claustro, era tomada del altar y llevada en procesión por las hermanas ${ }^{59}$. Las huellas de desgaste de la parte superior del torso del Crucificado muestran claramente que en estas ocasiones la cruz era besada o por lo menos tocada ${ }^{60}$.

57 Sobre el gran crucifijo de la iglesia conventual de St. Katharinental, A. Knoepfli, Die Kunstdenkmäler des Kantons Thurgau, pp. 229-231, sobre el crucifijo del llamado Maestro de Liebenfelser ibidem, pp. 235 y 239 y ss. Véase también Krone und Schleier, pp. 409-412.

${ }^{58}$ La cruz está hecha con tablas de madera de haya, mide 99,3x67 cm, en tablas de un grosor de 2,3-2,5 cm; una descripción detallada en A. Knoepfli, Die Kunstdenkmäler des Kantons Thurgau, pp. 204-206. La datación oscila entre 1250 y 1290; se cree que el lugar de produción ha de ser en general el espacio en torno al lago de Constanza, pero existe acuerdo en que este tipo de cruz con aplicaciones en forma de perlas se remonta a un prototipo italiano. Véase F. Maurer, Zum bemalten Katharinentaler Kruzifix; R. Schneider Berrenberg, Gemalte Kruzifixe außerhalb Italiens; Krone und Schleier, pp. 408 y ss.

59 Véase C. Jäggi, Architecture et disposition liturgique, p. 103 (prozessionale des 14. Jhs. aus Oetenbach, Bayerische Staatsbibl. München cgm. 168); véase también C. Jäggi, Frauenklöster im Spätmittelalter, pp. 252-255.

${ }^{60}$ A. Knoepfli, Die Kunstdenkmäler des Kantons Thurgau, p. 205. 


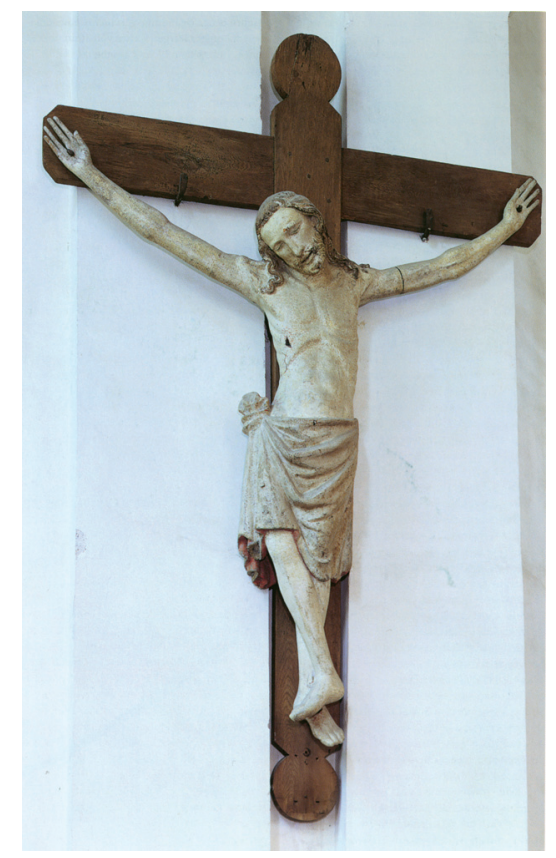

Fig. 7. Crucifijo de la iglesia de St. Katharinental 1300.

St. Katharinental, antigua iglesia monástica. Foto: Hauser und Eisenhut, St. Gallen.

Pero de las Vidas pueden extraerse todavía más referencias a las obras de arte existentes en St. Katharinental y a la relación que las monjas mantenían con ellas. Así por ejemplo, en la Vida de Mechthild, "la Caballera", se habla de una imagen del Señor en el sepulcro al que Mechthild se volvía en sus oraciones, tomando entre sus manos las manos y pies del Señor ${ }^{61}$. Probablemente, esta figura de Cristo pertenecía al Santo Sepulcro del que proceden también las de los dos ángeles de la Liebighaus de Frankfurt, fechados hacia 1330 y que, al contrario que la de Cristo, sí que se han conservado ${ }^{62}$.

61 "Si was ovch ze einem mal an ir gebett vor einem bild, da vnser herr in dem grab lit, vnd nam vnsers herren hend und fuess in ir hend"; R. Meyer, Das "St. Katharinentaler Schwesternbuch", p. 133. La Vida de Mechthilt der Rittrin pertenece asimismo a el corpus original; ibidem, p. 26.

62 Los dos ángeles están hechos de madera de tilo y miden apenas $115 \mathrm{~cm}$ de alto; A. Knoepfli, Die Kunstdenkmäler des Kantons Thurgau, p. 238; D. Zinke, Liebighaus - Museum alter Plastik. Nachantike großplastische Bildwerke, pp. 164-166, Kat. Nr. 83 y 84; Krone und Schleier, p. 416. 


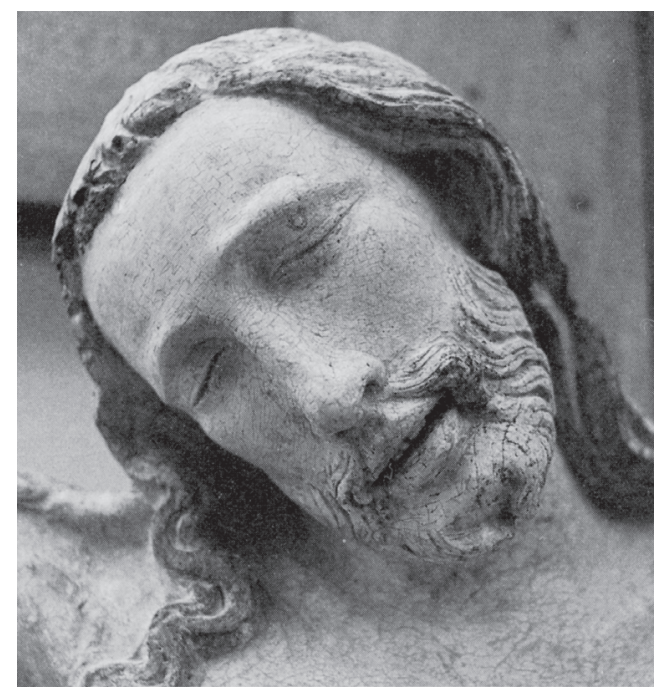

Fig. 8. Detalle del llamado "gran crucifijo" (véase fig. 7).

St. Katharinental, antigua iglesia monástica. Foto: Knoepfli 1989.

Si es exacta la hipótesis de Karl Frei-Kundert, según la cual el Cristo de Mechthild es idéntico al ataúd mencionado en el registro de sacristía de 1589, del que formaba parte también una tabla pintada, deberíamos entonces imaginarnos una estructura parecida a la de los Santos Sepulcros de Wienhausen (Luneburger Heide) y de Maigrauge (en Friburgo/Suiza) (fig. 10), y podríamos suponer que en St. Katharinental la obra estaría colocada, como allí, en el coro de las monjas ${ }^{63}$. Según consta, en el coro de las monjas había una imagen de María Magdalena penitente arrodillada ante Cristo que le absolvía de sus pecados; sin embargo, no queda claro si se trataba de una tabla o un fresco con la representación del banquete en casa de Simón el Fariseo o de un grupo escultórico con los dos protagonistas aislados. Ante esta imagen oraba Mia Goldastin y le pedía al Señor que le absolviese también a ella de todos sus pecados tan plena y puramente como habían sido absuelta María Magdalena ${ }^{64}$. La hermana Hilti Brümsin ejecutaba su plegaria ante

${ }^{63}$ K. Frei-Kundert, Zur Baugeschichte des Klosters St. Katharinental, pp. 33 y ss. y p. 155 ("ffir den sarch j gemaletti daflen").

64 "Do si ze einem mal stuend in dem kor an ir gebet vor einem bilde, das was sant Maria Magdalena als si zuo vnsers herren fuessen viel vnd ir vnser herr all ir súnd vergab, vnd dis viel ir vast in vnd begert von allen irem hertzen mit grosser begird, das ir vnser herr all ir súnd vergebe als luterlich als sant Marien Magdalenen. Vnd als si in dir grossen hertzklichen begird 
una imagen de Jesús en la columna y le imploraba la gracia de poder experimentar los dolores y la amargura por él sufridos durante la flagelación, lo que le fue acordado ${ }^{65}$. Finalmente Anne de Ramschwag en Pascua se arrodilló después de maitines ante una imagen de la Resurrección y meditó acerca de las palabras que Nuestro Señor dijo a sus amados discípulos después de resucitar de la muerte ${ }^{66}$. Lamentablemente no nos ha llegado ninguna de estas obras. Se ha conservado en cambio la bella Visitación (fig. 11), hoy en el Metropolitan Museum de Nueva York, generalmente fechada en torno a $1310 / 20$, y por tanto algo posterior a las obras ya mencionadas atribuibles al taller de Heinrich en Constanza ${ }^{67}$. Se desconoce su emplazamiento originario, pues no es mencionado en ninguna de las fuentes escritas, de lo que debemos deducir que o no se encontraba en la clausura sino en la iglesia exterior -en el espacio de los laicos- o no jugaba un papel importante en la praxis devocional de las monjas de St. Katharinental, o por lo menos no ha dejado memoria de ninguna experiencia significativa.

Si tomamos ahora en consideración estos ejemplos en relación a las preguntas formuladas al principio sobre las temáticas iconográficas y el contexto funcional en el que las obras de arte fueron "utilizadas" por las monjas, se cae en la cuenta de que en St. Katharinental son sobre todo el crucifijo y las imágenes de Madre de Dios los motivos visuales claramente manifestados en las Vidas como los más buscados y apreciados por las monjas. Ante ellos rezaban las monjas cuando estaban enfermas o afligidas y esperaban consuelo y curación, a ellos se volvían cuando la parentela les causaba preocupación o

was, do hort si ein stimm, die sprach: «Dir sind alle din súnd vergeben»".; R. Meyer, Das "St. Katharinentaler Schwesternbuch", p. 123. Sobre la pertenencia de esta Vida al corpus original véase ibidem, p. 25.

65 "Ein swester dú hiess swester Hilti Brúmsin. Die bettet eins tages vor einem bild, da vnser herr an der sule stuond, vnd begert von allem iren hertzen, das ir vnser herr geb ze empfinden des seres vnd der bitterkeit in der er was in dem zit, do er an der sul stuond. Das gewet si vnser herr, vnd wurden all ir inaeder vnd allú irú gelider als gar durch gossen mit grosser pin vnd bitterkeit, das si empfintlich empfant der marter, die vnser herr laid, do er an der sul stuond, als vil als es ir mvglich was zu enpfindenn"; R. Meyer, Das "St. Katharinentaler Schwesternbuch", p. 111. Perteneciente asimismo al corpus original; ibidem, p. 25.

66 "Das ander ward ir geben an dem heiligen tag ze ostran, do si nach der metti knúwet vor einem bild vnsers herren vrstendi vnd gedaht an das wort, das vnser herr zuo sinen lieben jungern sprach, do er erstuond von dem tod (...)"; R. Meyer, Das "St. Katharinentaler Schwesternbuch", p. 132. Sobre la pertenencia de la Vida de Anne de Ramschwag al corpus original véase más arriba n. 38.

${ }^{67}$ Ambas figuras miden $59 \mathrm{~cm}$ de alto; originalmente los niños eran visibles en forma de pequeñas figurillas tras el vidrio, remplazado en 1907 por cabujones de cristal de roca; acabado original; A. Knoepfli, Die Kunstdenkmäler des Kantons Thurgau, pp. 236-238. Véase también Krone und Schleier, pp. 414 y ss. 


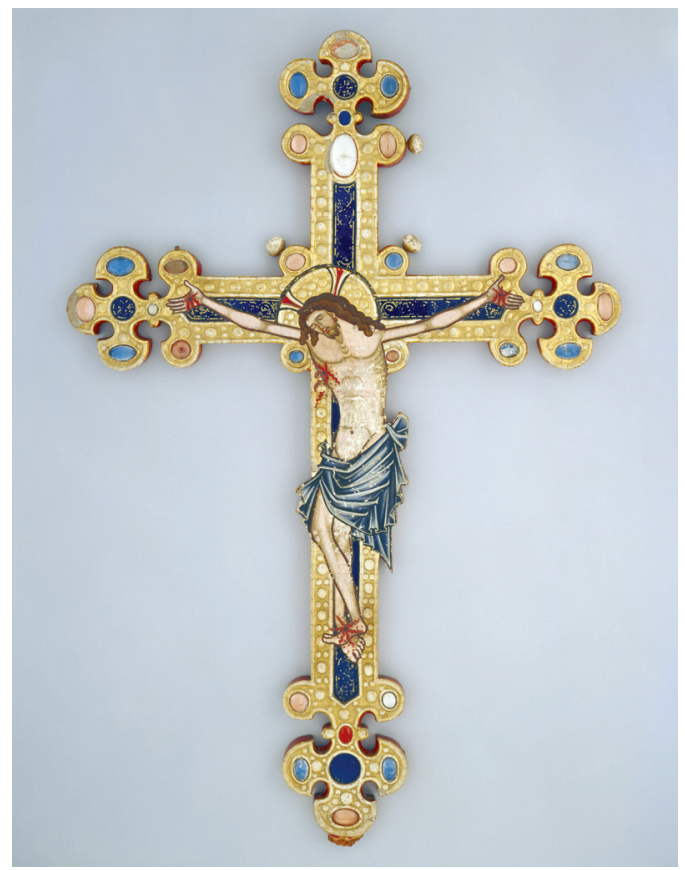

Fig. 9. Cruz de altar o procesional de St. Katharinental hacia 1250/1270. Basilea, Historisches Museum, Inv.-Nr. 1905-1970. Foto: M. Babey, Hist. Mus. Basel.

les asaltaban dudas sobre su propia vocación. Parece como si a Cristo, que con su sacrificio había tomado sobre si el mayor dolor posible, se le creyera capaz por su propio sufrimiento de la máxima comprensión. María, por su parte, era reivindicada sobre todo como maternal consoladora, y se tiene la impresión de que ella actuaba casi como interlocutora real asumiendo así el papel que les estaba vedado a las hermanas de comunidad a causa del precepto de silencio prescrito por la regla. Aquí nos encontramos ante una forma de comprensión de las imágenes que desde el inicio del arte cristiano la Iglesia oficial había tolerado sólo con gran desconfianza: es decir, la que equipara la imagen con el modelo original, o la que identifica la persona representada con su representación artística. Cuando las monjas, de rodillas ante una imagen de María o del crucifijo, dialogaban con ella, hablaban en realidad con la Madre de Dios o con el Crucificado y los percibían como presentes. No se trata pues aquí de la imagen como imagen devocional en el sentido de un medio para estimular la meditación, ni de la imagen como mediadora en la contemplación de los acontecimientos de la historia de salvación con vistas a su imitación mental, como 
a menudo postula la investigación de manera quzá demasiado exclusiva si se trata de obras de arte en los conventos de mujeres ${ }^{68}$. No se puede negar que este otro uso de las imágenes también existió: piénsese en aquella monja que oraba ante la imagen de Cristo en la columna de la flagelación e imploraba sentir en su propio cuerpo el sufrimiento del Señor ${ }^{69}$. En este caso no se trata en primer término de un dialogo con la persona representada, sino de la contemplación de una verdad salvífica y de una inmersión en el contenido de la imagen a fin de una imitatio Christi y en último término de la unio mystica-que es lo que se considera comúnmente característico de una "imagen devocional"70. Lo mismo puede decirse del Cristo resucitado, ante el que la hermana Anne de Ramschwag recordaba lo que les había dicho Cristo a los discípulos después de su resurrección ${ }^{71}$. Repetidas veces en las Vidas de las monjas de St. Katharinental se habla de recordar y de observar los sufrimientos de Cristo, pero en ninguna otra ocasión parece haber estado implicada una obra figurativa real $^{72}$. De la Vida de Gutta Mestin se puede incluso concluir que durante sus contemplaciones Gutta no tenía delante de sí ninguna imagen real, sino que simplemente lograba abismarse tan profundamente en sus pensamientos que el objeto de su meditación le era tan presente en un modo espiritual, como si lo viera con los ojos exteriores ${ }^{73}$. El hecho de que los ejercicios contemplativos de la compañera de Gutta, Anne de Ramschwag, tuvieran lugar después de maitines, la hora de plegaria en común a medianoche, demuestra además que se trataba de una práctica devocional privada, pues el tiempo reservado para la meditación y la oración privada según los estatutos de la Orden era después de

${ }^{68}$ Véase por ejemplo V. Kaiser, Zur Funktion der Christus-Johannes-Gruppe, p. 55.

${ }^{69}$ Véase n. 65.

${ }^{70}$ Véase por ejemplo R. Suckale, Arma Christi.

${ }^{71}$ Cotejar más arriba con la n. 66.

72 Véase por ejemplo R. Meyer, Das "St. Katharinentaler Schwesternbuch" p. 119 ("Ze einem mal was si (Elsbeth von Stoffeln, C. J.) nach metti an ir gebett vnd vberdaht vnd betrahtet vnsers herren marter vnd sin heiligen vrstendi vnd vffart. Vnd kam dar an, das vnser herr sinen heiligen gaist sinen jungern sant, vnd begert von vnserm herren, das er ir gebe ze gedenken, dar an si andaht hatt von dem heiligen geist.."; véase también ibidem, p. 111 ("Sy (Hilti Brümsin, C. J.) was ze einem mal an ir gebett vnd gedacht an vnsers herren marter vnd begert ze wissenn von vnserm herren, was si svgen soelti vss sinen wunden"). Lo mismo puede decirse para Engeltal: Ph. Strauch (ed.), Die Offenbarungen der Adelheid Langmann, pp. 7 y 23.

73 R. Meyer, Das "St. Katharinentaler Schwesternbuch", pp. 157 y ss. ("Ain schwester fraget sy (= Gutta Mestin, C. J.) von dem gebet, das sy tet, so sy als spat nider gieng. Do sait sy ir vnd sprach: «Jch gon mit miner betrachtung fvr vnsern heren, als er zuo tisch sass mit sinen lieben jungern (...), vnd gedenk an die grundlosen min, die er jnen entzogt (...). Vnd gedenk, wie der gemint junger sant Johannes da suesseklichen ruowet vff dem zarten hertzen vnsers heren. Vnd dis wirt mir dik in gaistlicher wis als gegenwúrtig, als ob ich es mit minen liplichen ogen saeche. (...) Dar nach gon ich mit betrachtung mit vnserm heren vff den berg (...). Vnd ich durch gon alles das liden vnsers heren mit betrachtung...»"). 
completas y de maitines ${ }^{74}$. Faltan en cambio por completo indicaciones de que las obras de arte jugaran también algún papel en los ejercicios de meditación colectivos - por ejemplo en relación con el oficio de María o de la Cruz, en los cuales a cada hora canónica iba asociada la rememoración de una estación de la Pasión de $\mathrm{Cristo}^{75}$, lo cual no excluye que algunas de las monjas fijasen su atención en alguna de las muchas obras de arte presentes en el coro ${ }^{76}$. Pero no se puede documentar con seguridad.

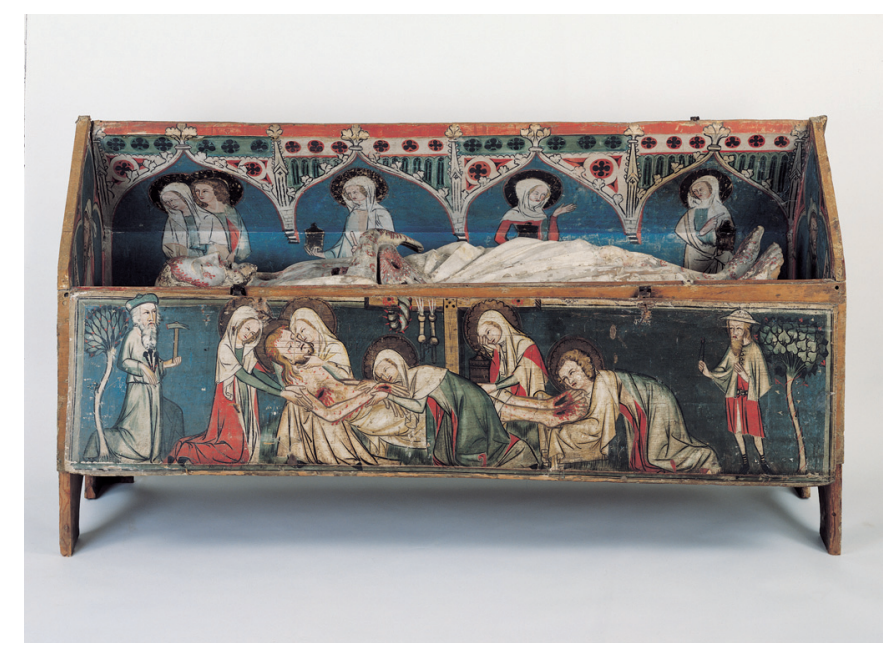

Fig. 10. "Santo sepulcro" o "sepulcro de Pascua" de Maigrauge, posterior a 1329. Friburgo, Museum für Kunst und Geschichte, Inv. Nr. MAHF 1995-38.

(c) Musée d'art et d'histoire de Fribourg. Foto: Primula Bosshard.

${ }^{74}$ Así, en la regla de San Sixto, cita de A. Simon, L'Ordre des Pénitentes, p. 152: "Post Completorium et Nocturnos, horam unam habebunt sorores, qua oracioni, contemplacioni ac devocioni possunt vacare". Tambien la oración de Richmut ante el crucifijo en el claustro tiene lugar despues de maitines, mientras que Gertrud de Herblingen recita su oración penitencial ante el crucifijo tras Completas; véase más arriba n. 49 y 52.

75 Véase por ejemplo "Metti vnser lieben frowen siben zit" de Unterlinden, impreso por A. M. P. Ingold, Le Liber Miraculorum d'Unterlinden, pp. 112-114. Allí se conmemora ("betrachtet", es decir, "contempla") en maitines el prendimiento de Cristo, en prima Cristo ante Caifás, en la hora tercia Cristo escarniado y la corona de espinas, en la sexta la crucifixión, en la nona la muerte de Cristo, en vísperas el descendimiento de la cruz y en completas la sepultura y se llora de aflicción con María los dolores entonces padecidos. Véase también F. Rapp, Zur Spiritualität in elsässischen Frauenklöstern, p. 358 y J.M. Plotzek, Andachtsbücher des Mittelalters, pp. 29 y ss.

${ }^{76}$ Véase n. 79. 


\section{TÖSs, ENGELTAL, KirCHBERG \& CO.}

St. Katharinental no es un caso aislado en relación al uso que las mujeres enclaustradas hacían de las obras de arte que les habían sido confiadas. Una valoración de los restantes Libros de monjas del siglo XIV ofrece resultados muy semejantes. También en Töss ${ }^{77}$, Unterlinden ${ }^{78}$, Adelhausen, Engeltall $^{79}$, Kirchberg junto a Sulz ${ }^{80}$, Ulm o Goteszell ${ }^{81}$ y en los restantes conventos

${ }^{77}$ F. Vetter (ed.), Das Leben der Schwestern zu Töss, p. 23 (crucifijo en la bodega contra los malos espíritus); p. 24 (crucifijo en el coro e imagen de María "uff der kapell", es decir en el coro alto o en una capilla lateral); p. 27 ("Sy bettet och gewonlich vor únser frowen bild in der capell da die dry kúng stant”); p. 28 (imagen de Nuestra Señora en el coro); p. 88 (gran crucifijo ¿con ojos móviles?); p. 107 (imagen de María sobre el altar del coro).

${ }^{78}$ Sor Gertrudis de Brugge: "Stabat namque quodam tempore in choro ante ymaginem uirginis gloriose, precibus et lacrimis immensis eandem uirginem piissimam deuotissime implorans, ut ipsa sibi delictorum suorum ueniam et salutem anime sue clementer dignaretur a filio suo dulcissimo impetrare. Cumque in feruore huius oracionis ualde suspensa foret, inuocando nunc nomen Domini Ihesu Christi, nunc uero matrem misericordie affectuosissime interpellando, repente corporeis oculis uisibiliter conspexit, quod ymago puiri Ihesu in gremio uirginis matris sedentis, manum suam eleuando sibi porrexit, dicens clara uoce admodumque suavi: (...)"; J. Ancelet-Hustache (ed.), Les "Vitae Sororum" d'Unterlinden, p. 414.

79 "An dem andern tag do saz di swester vor eim crucifixus..."; Ph. Strauch, Die Offenbarung der Adelheid Langmann, p. 38. Véase ibidem, p. 43: "eins tages unter einer messe in der vasten vor eim crucifixus do wart ez ir benomen ...". Este (u otro crucifijo) servía como destinatario cuando "iht anfehtung hot": "der sol gen für ein crucifixus und sol lesen den salme Deus deus meus respice und di antiphen Cristus factus est pro nobis obediens usque ad mortem, mortem autem crucis und sol si sibenstunt sprechen mit siben venien: di fünf den heilgen fünf wunden unsers herren und eine seim haupt und eine allen sein glidern, und sol sprechen: in leiden pin ich bewunden, ein kreutz hon ich in mir funden in meines leidens not, do hilf mir herre Jesus Crist auz durch dein pitterlichen tot. daz sprich all tag, so kumstu uz allem deim leiden". Véase. ibidem, p. 61: “...und eins tages do si in iren leiden was, do ging si hintz kirchen für ein crucifixus. do petet si gewonlichen vor, swenn si in grozzen leiden was". Véase K. Schröder (ed.), Büchlein von der Genaden Uberlast, p. 12: "Da ward sie so sere betrüebt daz sie ging fur ein crucifix daz man noch fur laitet". Para la crítica de las fuentes del Libro de monjas de Engeltaler véase S. Ringler, Quellen und Studien zur Viten und Offenbarungsliteratur, pp. 64-91; G. J. Lewis, By Women, for Women, about Women, pp. 19 y ss.; J. Thali, Beten - Schreiben Lesen, pp. 288-290.

${ }^{80}$ En Kirchberg había una imagen de la Madre de Dios en el coro de las monjas, ante la que una Navidad la hermana Guota de Hasslach rezó así: "Einesmahls als sie zue Weyhenachten sehr schwach im Chor vor einem Mutter Gottesbild stuende und sie ihrer Schwachheit ermandte, wie auch hilff und Trost durch ihr liebreiches Kindelein begerte und durch die grosse Freiden, die sie mit ihm auf Erden hatte, ist sie ihr leiblich mit ihrem Kindelein erschienen...."; A. Birlinger, Die Nonnen von Kirchberg bei Haigerloch, p. 8. Para la crítica de las fuentes del "libro de monjas" de Kirchberg, H.-P. Müller, Das Schwesternbuch von Kloster Kirchberg; S. Ringler, Quellen und Studien zur Viten- und Offenbarungsliteratur, pp. 91-110; G.J. Lewis, By Women, for Women, about Women, pp. 19-21.

${ }^{81}$ En el llamado Nonnenbuch (Libro de monjas) de Ulm, que H.-P. Müller, Das Schwesternbuch von Kloster Kirchberg, pp. 47 y ss., K. Graf, Die Nonnenviten aus Gotteszell y G.J. Lewis, By Women, for Women, about Women, pp. 16 y ss. creen que procede al menos como hipótesis de Gotteszell en el Gmünd suabo, se narra la siguiente historia: la hermana Elsbeth ("Elsbetlein") fue una vez al coro, "da stund sie vor einem crucifix, das was gar peinlich und jemerlich gemalet", y permaneció ante él "in gar grosser andacht, und was nyemant mer in dem 
fueron sobre todo imágenes de María y el crucifijo las que jugaron un papel en la experiencia de gracia de las monjas y, de nuevo, estas imágenes aparecen mencionadas sobre todo en el contexto de ruegos personales de consuelo, sanación y remisión de los pecados ${ }^{82}$. Margaret Ebner, monja en la comunidad de dominicas Maria Mödingen de Baviera, parece que acostumbraba a permanecer en pie ante un gran crucifijo en el coro, hablando con el Crucificado y pidiéndole que la tomará consigo; obviamente en esas ocasiones deseaba tocarlo pero no podía alcanzarlo porque era demasiado grande y estaba colgado demasiado alto ${ }^{83}$. La dominica de Engeltal Christine Ebner en una ocasión rompió a llorar de aflicción tan amargamente ante un crucifijo que le mojó los pies $^{84}$. De la hermana Bethe Vinchin de Adelhausen también se cuenta que, estando desde hacía poco en el convento y no alcanzando a adaptarse, en su soledad, iba a rezar con frecuencia ante un crucifijo con el que hablaba como con un amigo quejándose de que le afligía no tener a nadie que le quisiera bien y le consolase ${ }^{85}$. Pero la imagen del crucifijo servía en Adelhausen también

kor denn ein swester, die stund wol so ferr von ir, das si getrauet, das sie not möchte gehoren, wie sie unsern herren mit worten seiner genaden pete. Und ving an, und manet unsern herrn mit tieffem seüfczen aller seiner leidunge, und pat in, das er ir sünde vergebe". Lo ve acto seguido como un leproso y lo atribuye a su propia pecaminosidad entonces vuelve a verlo hermoso, lo cual era un signo de que Cristo le había absuelto de todos sus pecados. "Und dar nach, da die swester vor ir andacht was auff gestanden, do het ir die ander swester, die auch in dem kor was, gut war genumen, und hörte auch, wie sie mit unserm herren redte"; F.W.E. Roth, Aufzeichnungen über das mystische Leben, p. 143. Sobre la separación del "Ulmer Schwesternbuchs" de las Vidas de Kirchberg Viten véase también S. Bürkle, Literatur im Kloster, pp. 172 y ss., 325 y ss.

${ }_{82}$ Curiosamente, tambien en el interior de las "pequeñas imágenes devocionales" que se hallaron en el coro de las monjas del monasterio cisterciense de Wienhausen entre las grietas del suelo, son las representaciones de María y del crucifijo, junto con las de la Verónica, los temas iconográficos más comunmente encontrados; H. Appuhn, Ch. Heusinger, Der Fund kleiner Andachtsbilder, p. 166.

${ }^{83} \mathrm{Ph}$. Strauch, Margaretha Ebner und Heinrich von Nördlingen, p. 21 ("nun heten wir ain grozz cruzifixus in dem cor. da het ich die grösten begird, daz ich ez solt küssen und an min hercz solt druken als diu andern. do was ez mir ze grozz und ze hoh") y p. 77 ("Ich suond ze ainem mal in dem cor vor dem crucifixus und begert mit grossem ernst, daz er mich hin zuo im nem"). Es en este contexto se debe hacer referencia al Cristo gótico del convento de clarisas de Brixen fechado hacia 1360, que dejaba ver en la zona de los pies las huellas de una intensa adoración; L. Andergassen, Leo (Hg.), Icones Clarae, p. 123.

84 "Da sie gehorsam solt tun, do wolt die priolin ir gehorsam niht nehmen, do von daz ir vater der siechen leuten waz. Da ward sie so sere betrüebt daz sie ging fur ein crucifix daz man noch fur laitet, und waint als sere daz im sin füezz nazz wurden. Da nam unser herre die hant von dem creutz und riht sie selber auf und sprach zu ir: 'Riht dich auf, ich will dir selber einer gehorsam helfen"'; K. Schröder, Der Nonne von Engelthal Büchlein von der Genaden Uberlast, p. 12.

85 "Ein swester hies swester Behte Vinchin. Do die zum ersten in das closter kam, do wz si in grossem er nste vnd in grosser andacht, vnd hatt nieman, von dem si kein liep hette, vnd das tet ir dicke gar we. Also hatten si ein crucifix, fúr dz gie si gar dicke betten, vnd rette mit ime als ein frund mit dem andern, vnd clagte ime, wz si zuo betrübe angie, vnd sprach: «Lieber Herre, nu han ich nieman, wann dich, nu tuo mir gütlich vnd tröste mich». Dis tet si gar dicke, vnd da zuo einem male wart, do neiget vnser Herre sin houbet ab dem crutz vff ir wange, vnd sprach zuo 
como instrumento de meditación en el camino de la unio mystica, aspirando a ser una con Dios: Una vez que la hermana Metze Tüschelin se encontraba delante de la cruz, el martirio de Nuestro Señor -su Pasión y en especial su crucifixión- le llegó al corazón e imploró sentir el sufrimiento de Dios en su propio cuerpo ${ }^{86}$. Seguramente esto aconteció en el contexto de una oración privada más o menos estandarizada sobre la Pasión de Jesús, como la transmitida de forma explícita por su compañera Geri Küchlein; ésta rezaba con especial fruición los dolores de Nuestro Señor. Una vez, estando ante el crucifijo, abismada profundamente en su oración, Cristo se inclinó desde la cruz volviéndose hacia ella ${ }^{87}$. De un texto estandarizado debía tratarse también en el caso dela oración pintada a pincel en la pared junto a la Verónica que estaba colgada en el claustro de Töss delante de la sala capitular; Anna Wansaseller procuraba recitarla cada vez que estaba en oración ante la sagrada $F a z^{88}$. En Töss había además una imagen que mostraba a Jesús ante el tribunal, quizá la representación del Ecce Homo o una representación del Juicio Final, a la cual la hermana Margret Willin rogaba interiormente que quisiera juzgarla con benevolencia el día del juicio ${ }^{89}$. Por el contrario, imágenes devocionales -desde el punto de vista de la historia del arte- "clásicas" como la Pietà, Cristo y Juan, o la Visitación, en las que el diálogo venía ya dado por el contenido de la imagen, no se mencionan en ninguno de los Libros de monjas. Esto no quiere decir que no hubiera imágenes de este tipo, pero para el contacto directo con la Divinidad, para la oración privada o para la oración personal ligada a la experiencia de la gracia no parecen haber jugado en estos conventos un papel digno de mención; no al menos a tenor de lo manifestado por las Vidas sobre las que me he basado.

ir: «Du solt wissen, das ich dich niemer wil gelan»"; J. König (ed.), Die Chronik der Anna von Munzingen, p. 174.

86 "gieng ir vnsers Herren marter zuo hertzen, vnd begerte ze wissende, da mitte si aller nechste Gott sinre marter möhte gedenken"; J. König (ed.), Die Chronik der Anna von Munzingen, p. 161.

87 "Die bettete sunderlich gerne vnseres Herren marter. Vnd zuo einem male, do stuond sie vor einem crúcifixe vnd bettete gar ernst, vnd vnser Herre der neiget sich ab dem crútze gen ir"; J. König (ed.), Die Chronik der Anna von Munzingen, p. 185. Lo mismo se narra para Engeltal; véase más arriba n. 92 y Ph. Strauch (ed.), Die Offenbarungen der Adelheid Langmann, pp. 80-91. Que la unio mystica se podía alcanzar plenamente durante la oración, no siendo separables la orción privada y la meditación en general, lo demuestra también la Vida de Adelheit der Huterin en el Schwesterbuch de St. Katharinental; R. Meyer, Das "St. Katharinentaler Schwesternbuch", p. 135.

88 "Nun hat sy (= Anna Wansaseller, C.J.) die gewonhait das sy gar dik bettet vor dem antlút das vor dem capitelhus hanget, das selb gebet das da by geschriben stat: «Salve summe deitatis»"; F. Vetter (ed.), Das Leben der Schwestern zu Töss, p. 46.

89 "Sy hat och sunderlich andacht ze ainem bild als únser herr vor gericht stuond, und bat in denn gar inneklich das sy an dem jungsten gericht genaedeklich gerichtet wurdy"; F. Vetter (ed.), Das Leben der Schwestern zu Töss, p. 27. 


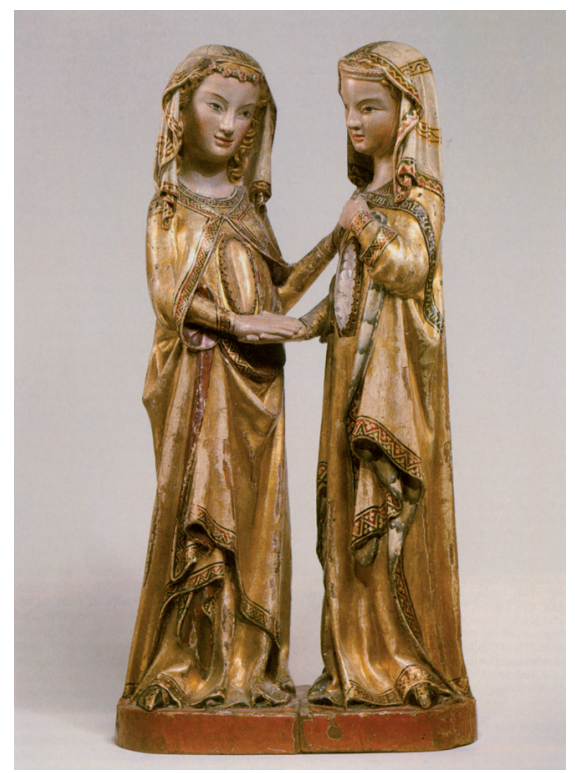

Fig. 11. Visitación, fechada alrededor de 1320.

Nueva York, Metropolitan Museum of Art, Inv.-Nr. 17.190.724. Foto: Knoepfli 1989.

\section{RESUMEN Y CONCLUSIÓN}

Las fuentes escritas que hemos examinado ponen de manifiesto que en los conventos de dominicas de Teutonia de la Edad Media tardía las obras de arte parecen haber sido apreciadas sobre todo como interlocutoras en las oraciones rogativas de carácter privado. Muchas de las hermanas tenían santos personales favoritos a los que dirigirse preferentemente ${ }^{90}$. Especialmente amados como fuente de ayuda y consuelo eran María y el crucifijo. Hasta qué punto estas imágenes eran equiparadas a aquellos a quienes representaban lo testifica un suceso acontecido en Unterlinden, donde una monja, que dudaba del poder milagroso de una imagen de María conservada en el convento, fue alcanzada por la sordera y pensando en su curación alabó a la imagen pro-

${ }^{90}$ Así por ejemplo se cuenta de la hermana de Engeltal Diemut Ebnerin de Nürnberg, que "dem heiligen Gervasio alle tag etwaz betet", el compañero de Gervasio, Protasio, se sintió humillado y se quejó ante ella y le exigió que lo tomara en consideración también a él, pues al final él estaba igual de alto en el cielo "in dem himel als hoch als er"; K. Schröder, Der Nonne von Engelthal Büchlein von der Genaden Uberlast, p. 33. Véase también -para St. Katharinental- R. Meyer, Das "St. Katharinentaler Schwesternbuch", p. 103 (Santa Catalina) y p. 175 (San Juan Bautista). 
metiéndole a partir de entonces honrarla con asidua plegaria y sacrificios ${ }^{91}$. Ya en relación a las disputas entre el obispo de Estrasburgo y el Emperador Rodolfo de Habsburgo (1261) en Unterlinden se había apelado a la Madre de Dios, a través de su imagen y, al instante, la priora, en vistas del peligro inminente, había dado la vuelta tres veces al convento portando en procesión la imagen de María ${ }^{92}$. En la misma dirección se inscribe también un suceso que nos llega de St. Katharinental: hacia finales del siglo XIV el convento se dividió en dos facciones que habían tomado por guía respectivamente a San Juan Evangelista y a San Juan Bautista. En una ocasión -narra la Vida de Clara Anna de Hohenberg- el día de la fiesta de Juan el Bautista, sucedió que Clara Anna, encontrándose con algunas hermanas de la comunidad en el claustro ante una imagen pintada de Juan Bautista, explicó con orgullo por qué prefería a Juan Evangelista: ¡Mirad que leñador! ofendiendo así la imagen del santo, por lo que desató la cólera divina que le abatió dejándola sordomuda hasta que alabó a la imagen, prometiéndole a partir de entonces honrar también a Juan el Bautista ${ }^{93}$. Con esta desgracia -esta es la moraleja de la historia- llegaron a su fin las riñas entre las monjas y de ahí en adelante ambos santos fueron honrados por igual ${ }^{94}$.

Podemos preguntarnos en conclusión, hasta qué punto la forma de entender las imágenes, o el uso de las mismas que estas historias manifiestan, puede ser considerada "típicamente" femenina y en consecuencia no van a encontrarse en los conventos masculinos. En mi opinión, esta diferencia se subraya a menudo excesivamente. Por ejemplo cuando el general de la Orden dominica, Humberto de Romans, en sus estatutos de 1259 prescribe a sus

${ }^{91}$ A.M.P. Ingold, Le Liber Miraculorum d'Unterlinden, p. 108 ("gelobet (...) an die selbliche egenanten Statt ir bilde flisseclichen zu eren mit gebette vnd oppfere").

92 "Accepit igitur ymaginem eiusdem virginis gloriose cum multa reuerencia ac pia nimis conficencia totum monasterium eiusque omnes officinas (...) tribus uicibus deuotissime circuiuit"; J. Ancelet-Hustache (Hg.), Les "Vitae Sororum" d'Unterlinden, p. 392.

93 "Auff st. Johannes Pabtisttag begabe es sich, das die schwester Anna Clara nebent anderen schwestern sich jm Creützgang vor einem gemohlten bildnuss St. Johannes Pabtist stunde. Da sprach sie aus vbermuth, die weil sie mehr auff St. Johannes Euangelist hielt: «Schauet, wie dieser holzackher allda steht!» Aber gott straffte die verwegne red von stund an, weil er in allen seinen Heiligen will gelobt sein, wurde allso von einem vnsichtbohren streich vrplötzlich zu boden geslagen, das sie do lag mit offenen augen, konte weder ach noch wehe schreyen, verstunde auch nicht, was andre schwestern zu ihr redten"; R. Meyer, Das "St. Katharinentaler Schwesternbuch", p. 180. La Vida de Clara Anna de Hohenburg pertenece a una ampliación del Schwesternbuch de St. Katharinental; se encuentra por primera vez en 1468 en el Buch der Reformacio Predigerordens de Johannes Meyer y es probable que se incluyera en el Schwesternbuch solo en el siglo XVII; ibidem, p. 82.

94 "Durch diese haimsuchung wurde das gezanckh der anderen schwestern auffgehoben vnd beyde Heiligen jn gleichen ehren gehalten"; R. Meyer, Das "St. Katharinentaler Schwesternbuch", p. 180. Esta moraleja final muestra claramente la reelaboración de la Vida según el espíritu de la Reforma; véase más arriba n. 93. 
frailes hacer una reverencia ante el altar al entrar en el coro al crucifijo, a la imagen de María (imago B.Virginis) y a las imágenes de los restantes santos, tiene en mente exactamente la misma idea, es decir, que reverenciando a la representación se reverencia al arquetipo origina ${ }^{95}$. También la oración ante imágenes artísticas con el deseo de que la representada o el representado cobrara vida no se limitaba de hecho a los conventos femeninos; esto lo demuestran el Miracle de Notre Dame en donde se cuenta que un monje, tras la Vigilia, cuando los otros hermanos se habían ido ya a la cama, acostumbraba a rezar arrodillado ante una estatua de María y le pedía a la Madre de Dios que le entregase a su Hijo, y cada vez María se le aparecía después en sueños, justamente con el aspecto de la estatua venerada ${ }^{96}$. Por Cesario de Heisterbach sabemos de una figurita de marfil de la Virgen que era propiedad del también cisterciense Walter de Bierbeek; este la llevaba siempre consigo y una vez encontrándose en gran peligro la coloco delante de sí, se postró ante ella y le imploró auxilio ${ }^{97}$. ¡Estos comportamientos no están tan lejos del uso de las imágenes que hacían nuestras monjas! No hemos de perder de vista tampoco que las fuentes disponibles para los conventos femeninos difieren mucho de las de los conventos masculinos pues no existen equivalentes masculinos a los Libros de monjas. A diferencia de las monjas, a las que el registro de experiencias sobrenaturales en relación con las imágenes les había procurado la fama ya entre sus contemporáneas, haciéndolas finalmente inmortales hasta el día de hoy, un monje inteligente a ser posible se habría guardado bien de contar a otros o de transmitir por escrito a la posteridad experiencias semejantes, pues sabía muy bien que en los círculos de teólogos cultos solo la palabra valía como medio apropiado para el mensaje divino, mientras que las imágenes, a ojos de los representantes de las Órdenes como Guillermo de St-Thierry o Buenaventura, eran cosas adecuadas solo para aquellos que eran piadosos, pero aun no bien afianzados [en su fe $]^{98}$, es decir, los laicos, los novicios, y las monjas.

95 J.J. Berthier, Beati Humberti, p. 162. Véase también ibidem, p. 170: "Item, propter reliquias et imagines sanctas, quae solent in eo (i. e. altare, C. J.) vel iuxta esse; maxime autem propter Corpus Domini, quod ibidem reservatur". Que tambien en los conventos de mujeres se practicaba el saludo a las imagenes al entrar y salir del coro lo atestigua entre otros el de Töss; F. Vetter, Das Leben der Schwestern zu Töss, p. 27. Para más detalles también G.J.C. Snoek, Medieval Piety, pp. 246 y ss. y passim.

96 S. Ringbom, Icon to Narrative, pp. 17 y ss.

${ }^{97}$ A. Laabs, Malerei und Plastik im Zisterzienserorden, pp. 19 y ss. y p. 86; véase también ibidem, p. 191, n. 106.

${ }_{98}$ E. Vavra, Bildmotivik und Frauenmystik, pp. 225-227; J.F. Hamburger, The Visual an the Visionary, pp.187-190. 


\section{BIBLIOGRAFÍA CITADA}

Ancelet-Hustache, Jeanne (ed.), Les "Vitae Sororum" d'Unterlinden. Édition critique du manuscript 508 de la Bibliothèque de Colmar, "Archives d'histoire doctrinale et littéraire du Moyen âge" 5 (1930), pp. 317-509. Andergassen, Leo (ed.), Icones Clarae. Kunst aus dem Brixener Klarissenkloster, Brixen, Diözesanmuseum, 1999.

Appuhn, Horst; von Heusinger, Christian, Der Fund kleiner Andachtsbilder des 13. bis 17. Jahrhunderts im Kloster Wienhausen, "Niederdeutsche Beiträge zur Kunstgeschichte" 4 (1965), pp. 157-238.

Benz, Ernst, Christliche Mystik und christliche Kunst (Zur theologischen Interpretation mittelalterlicher Kunst), "Deutsche Vierteljahresschrift für Literaturwiss und Geistesgeschicht” 12 (1934), pp. 22-48.

Berthier, Joachim Joseph, Beati Humberti de Romanis quinti Praedicatorum Magistri Generalis Opera de Vita Regulari, vol. II, Roma, A. Befani 1889.

Birlinger, Anton, Die Nonnen von St. Katharinental bei Diessenhofen, "Alemannia. Zeitschrift für Sprache, Litteratur und Volkskunde des Elsasses und Oberrheins" 15 (1887), pp. 150-187.

Birlinger, Anton, Leben heiliger alemannischer Frauen des 14./15. Jhs.: Die Nonnen von Kirchberg bei Haigerloch, "Alemannia. Zeitschrift für Sprache, Litteratur und Volkskunde des Elsasses und Oberrheins" 11 (1883), pp. 1-20.

Blank, Walter, Dominikanische Frauenmystik und die Entstehung des Andachtsbildes um 1300, “Alemannisches Jahrbuch" (1964-1965), pp. 57-86.

Boerner, Bruno, Le rôle de l'image sculptée dans les couvents féminins allemands à la fin du Moyen Âge, "Bibliothèque de l'École des Chartes" 162 (2004), pp. 119-131.

Bruzelius, Caroline, Hearing is Believing: Clarissan Architecture, ca. 12131340, "Gesta" 31/2 (1992), pp. 83-91.

Bürkle, Susanne, Literatur im Kloster. Historische Funktion und rhetorische Legitimation frauenmystischer Texte des 14. Jahrhunderts, Tubinga - Basilea, Francke, 1999.

De Coo, Jozef, Museum van den Bergh, Catalogus II: Beeldhouwkunst, Amberes, Museum van den Bergh, 1969, pp. 87-102.

Descoeudres, Georges, Mittelalterliche Dominikanerinnenkirchen in der Zentral- und Nordostschweiz, "Mitteilungen des Historischen Vereins des Kanton Schwyz” 81 (1989), pp. 39-77.

Dinzelbacher, Peter, Zur Interpretation erlebnismystischer Texte des Mittelalters, "Zeitschrift für deutsches Altertum und deutsche Literatur" 117 (1988), pp. 1-23. 
Eugster, Erwin; Baumer-Müller, Verena, St. Katharinental, en Helvetia Sacra, Abt. IV: Die Orden mit Augustinerregel, vol. V-2, Basilea, Schwabe, 1999, pp. 781-818.

Folini, Christian; Palaia, Alberto, Die Dominikanerinnenklöster Töss und St. Katharinental. Sozialgeschichtliche Annäherungen, en Signori, Gabriela (ed.), Lesen, Schreiben, Sticken und Erinnern. Beiträge zur Kultur- und Sozialgeschichte mittelalterlicher Frauenklöster, Bielefeld, Verlag für Regionalgeschichte, 2000, pp. 91-108.

Frei-Kundert, Karl, Zur Baugeschichte des Klosters St. Katharinental, "Thurgauische Beiträge zur vaterländischen Geschichte" 66 (1929), pp. 1-176.

Graf, Klaus, Die Nonnenviten aus Gotteszell bei Schwäbisch Gmünd. Zum Entstehungsort des sog. ,Ulmer Nonnenbuchs', "Rottenburger Jahrbuch für Kirchengeschichte" 3 (1984), pp. 191-195.

Grübel, Isabel, Bettelorden und Frauenfrömmigkeit im 13. Jahrhundert. Das Verhältnis der Mendikanten zu Nonnenklöstern und Beginen am Beispiel Strassburg und Basel, Múnich, Tuduv-Verlagsgesellsc-haft, 1987. (Kulturgeschichtliche Forschungen; 9).

Hamburger, Jeffrey F., The Liber miraculorum of Unterlinden: An Icon in Its Convent Setting, en Hamburger, Jeffrey F., The Visual and the Visionary. Art and Female Spirituality in Late Medieval Germany, Nueva York, Zone Books, 1998, pp. 279-316.

Hamburger, Jeffrey F., The Visual and the Visionary. Art and Female Spirituality in Late Medieval Germany, Nueva York, Zone Books, 1998.

Hamburger, Jeffrey F., Nuns as Artists. The Visual Culture of a Medieval Convent, Berkeley, University of California Press, 1997.

Hamburger, Jeffrey F., Art, Enclosure and the Cura Monialium: Prolegomena in the Guise of a Postscript, "Gesta" 31/2 (1992), pp. 108-134.

Hamburger, Jeffrey F.; Jäggi, Carola; Marti, Susan; Röckelein, Hedwig (eds.), Frauen - Kloster - Kunst. Neue Forschungen zur Kulturgeschichte des Mittelalters. Beiträge zum Internationalen Kolloquium vom 13. bis 16. Mai 2005 anlässlich der Ausstellung „Krone und Schleier“, Turnhout, Brepols, 2007.

Haussherr, Reiner, Über die Christus-Johannes-Gruppen. Zum Problem „Andachtsbilder" und deutsche Mystik, en Beiträge zur Kunst des Mittelalters. Festschrift für Hans Wentzel zum 60. Geburtstag, Berlín, Gebr. Mann, 1975, pp. 79-103.

Ingold, A. M. P., Le Liber Miraculorum d'Unterlinden, en Miscellanea Alsati$c a$, vol. III, Colmar, H. Huffer, 1897, pp. 97-116 y pp. 283-285.

Jäggi, Carola, Wie kam Kunst ins Kloster? Überlegungen zu Produktion und Import vom Werken der Bildenden Kunst in den Klarissen- und Do- 
minikanerinnenklöstern der Teutonia, "Rottenburger Jahrbuch für Kirchengeschichte" 27 (2008), pp. 91-109.

Jäggi, Carola, Frauenklöster im Spätmittelalter: Die Kirchen der Klarissen und Dominikanerinnen im 13. und 14. Jahrhundert, Petersberg, Imhof, 2006.

Jäggi, Carola, "Sy bettet och gewonlich vor únser frowen bild...”: Überlegungen zur Funktion von Kunstwerken in spätmittelalterlichen Frauenklöstern, en Schmitt, Jean-Claude (ed.), Femmes, art et religion au Moyen Âge, Estrasburgo, Presses Universitaires de Strasbourg, 2004, pp. 63-86.

Jäggi, Carola, Eastern Choir or Western Gallery? The Problem of the Place of the Nuns' Choir in Koenigsfelden and other Early Mendicant Nunneries, "Gesta" 40/1 (2001), pp. 79-93.

Jäggi, Carola, Architecture et disposition liturgique des couvents féminins dans le Rhin supérieur aux XIIIe et XIVe siècles, en Les dominicaines d'Unterlinden, Ausstellungskat. Musée d'Unterlinden Colmar (10 décembre 2000-10 juin 2001), vol. I, Paris, Somogy, 2000, pp. 89-105.

Kaiser, Veronika, "bild, da sant johans ruwet uff unser herren herczen-" Zur Funktion der Christus-Johannes-Gruppe, en Naredi-Rainer, Paul (ed.), Sinnbild und Abbild. Zur Funktion des Bildes, Innsbruck, Universität, 1994, pp. 51-62. (Kunstgeschichtliche Studien Innsbruck. Neue Folge; 1).

Knoepfli, Albert, Die Kunstdenkmäler des Kantons Thurgau, vol. IV, Basilea, Birkhäuser, 1989.

König, J. (ed.), Die Chronik der Anna von Munzingen, "Freiburger DiöcesanArchiv" 13 (1880), pp. 131-236.

Krone und Schleier. Kunst aus mittelalterlichen Frauenklöstern, Múnich, Hirmer, 2005.

Laabs, Annegret, Malerei und Plastik im Zisterzienserorden. Zum Bildgebrauch zwischen sakralem Zeremoniell und Stiftermemoria 12501430, Petersberg, Imhof, 2000.

Lentes, Thomas, Bild, Reform und cura monialium. Bildverständnis und Bildgebrauch im Buch der Reformacio Predigerordens des Johannes Meyer $(†$ 1485), en Eichenlaub, Jean-Luc (ed.), Dominicains et dominicaines en Alsace XIIIe-XXe siècles. Actes du colloque de Guebwiller (8-9 avril 1994), Colmar, Archives départementales du Haut-Rhin, 1996, pp. 177-195.

Lewis, Gertrud Jaron, By Women, for Women, about Women: The Sister-Books of Fourteenth Century Germany, Toronto, Pontifical Institute of Mediaeval Studies, 1996. (Pontifical Institute of Medieval Studies, Studies and Texts; 125). 
Maurer, François, Zum bemalten Katharinentaler Kruzifix, "Unsere Kunstdenkmäler" 20 (1969), pp. 57-65.

Meyer, Ruth, Das "St. Katharinentaler Schwesternbuch". Untersuchung, Edition, Kommentar, Tubinga, Niemeyer, 1995. (Münchener Texte und Untersuchungen zur deutschen Literatur des Mittelalters; 104).

Müller, Hans-Peter, Das Schwesternbuch von Kloster Kirchberg (1237-1305), "Der Sülchgau" 21/22 (1977-1978), pp. 42-56.

Plotzek, Joachim M., Andachtsbücher des Mittelalters aus Privatbesitz. Katalog zur Ausstellung im Schnütgen-Museum, Colonia, SchnütgenMuseum, 1987.

Rapp, Francis, Zur Spiritualität in elsässischen Frauenklöstern am Ende des Mittelalters, en Dinzelbacher, Peter; Bauer, Dieter (Hgg.), Frauenmystik im Mittelalter, Ostfildern bei Stuttgart, Schwabenverlag, 1985, pp. 347-365.

Ringbom, Sixten, Icon to Narrative: The Rise of the Dramatic Close-up in Fifteenth-Century Painting, Åbo, Akademi, 1965. (Acta Academiae Aboensis, Ser. A, Humaniora; 31-2).

Ringler, Siegfried, Quellen und Studien zur Viten- und Offenbarungsliteratur in Frauenklöstern des Mittelalters, Zürich, Artemis, 1980. (Münchener Texte und Untersuchungen zur deutschen Literatur des Mittelalters; 72).

Romano, Serena, Gli affreschi di S. Pietro in vineis, en Rak, Michele (Hg.), Il collegio Principe di Piemonte e la chiesa di S. Pietro in vineis in Anagni, Roma, INPDAP, 1997, pp. 101-117.

Roth, F. W. E., Aufzeichnungen über das mystische Leben der Nonnen von Kirchberg bei Sulz, "Alemannia. Zeitschrift für Sprache, Literatur und Volkskunde des Elsasses, Oberrheins und Schwabens" 21 (1893), pp. 103-148.

Schneider Berrenberg, Rüdiger: Gemalte Kruzifixe außerhalb Italiens. Ein Beitrag zur Verbreitung der croci dipinte', "Das Münster" 28 (1975), pp. 203-217.

Schröder, Karl (ed.): Der Nonne von Engelthal Büchlein von der Genaden Uberlast, Tübingen, Litterar. Verein, 1871. (Bibliothek des litterarischen Vereins in Stuttgart; 108).

Simon, André, L'Ordre des Pénitentes de Sainte Marie-Madeleine en Allemagne au XIIIe siècle, Friburgo, Oeuvre de Saint-Paul, 1918.

Snoek, Godefridus J. C.: Medieval Piety from Relics to the Eucharist: A Process of mutual Interaction, Leiden, Brill, 1995. (Studies in the History of Christian Thought; 63).

Strauch, Philipp: Margaretha Ebner und Heinrich von Nördlingen. Ein Beitrag zur deutschen Mystik, Friburgo de Brisgonia, 1882 (reimpr. Ámsterdam, 1966). 
Strauch, Philipp (ed.), Die Offenbarungen der Adelheid Langmann, Klosterfrau zu Engelthal, Estrasburgo, Trübner, 1878. (Quellen und Forschungen zur Sprach- und Culturgeschichte der germanischen Völker; 26).

Suckale, Robert, Arma Christi. Überlegungen zur Zeichenhaftigkeit mittelalterlicher Andachtsbilder, "Städel-Jahrbuch" 6 (1977), pp. 177-208.

Thali, Johanna, Beten - Schreiben - Lesen. Literarisches Leben und Marienspiritualität im Kloster Engelthal, Tubinga, A. Francke, 2003. (Bibliotheca Germanica; 42).

Thurgauisches Urkundenbuch, vol. III: 1251-1300, redigiert von Friedrich Schaltegger, Frauenfeld, Huber, 1925.

Thurgauisches Urkundenbuch, vol. IV: 1300-1340, redigiert von Friedrich Schaltegger, Frauenfeld, Huber, 1931.

Vassilevitch, Daria, "Schrei der Seele" oder didaktische Stilisierung? Schwesternbücher aus Dominikanerinnenklöstern, en Signori, Gabriela (ed.), Lesen, Schreiben, Sticken und Erinnern. Beiträge zur Kultur- und Sozialgeschichte mittelalterlicher Frauenklöster, Bielefeld, Verl. für Regionalgeschichte, 2000, pp. 213-229.

Vavra, Elisabeth, Bildmotivik und Frauenmystik: Funktion und Rezeption, en Dinzelbacher, Peter; Bauer, Dieter (eds.), Frauenmystik im Mittelalter, Ostfildern bei Stuttgart, Schwabenverlag, 1985, pp. 201-230.

Vetter, Ferdinand (ed.), Das Leben der Schwestern zu Töss, beschrieben von Elsbeth Stagel, samt der Vorrede von Johannes Meier und dem Leben der Prinzessin von Ungarn, Berlín, Weidmann, 1906. (Deutsche Texte des Mittelalters; 6).

Zimmer, Petra, Die Dominikaner und Dominikanerinnen in der Schweiz, en Helvetia Sacra, Abt. IV: Die Orden mit Augustinerregel, vol. V-1, Basilea, Schwabe, 1999, pp. 25-103.

Zimmer, Petra, Die Funktion und Ausstattung des Altares auf der Nonnenempore. Beispiele zum Bildgebrauch in Frauenklöstern aus dem 13. bis 16. Jahrhundert, Colonia, Universität zu Köln, 1990.

Zinke, Detlef, Liebighaus - Museum alter Plastik. Nachantike großplastische Bildwerke, vol. I, Melsungen, Gutenberg, 1981.

Zisterzienserbauten in der Schweiz. Neue Forschungsergebnisse zur Archäologie und Kunstgeschichte, vol. I: Frauenklöster, Zúrich, Verlag der Fachvereine, 1990. (Veröffentlichungen des Instituts für Denkmalpflege an der Eidgenössischen Technischen Hochschule Zürich; 10.1). 